\title{
Binuclear Cyclopentadienylmetal Carbonyl Hydrides of Iridium, Osmium, and Rhenium: The Effect of Electron Count on the Preferred Structures
}

\author{
Ziyuan Yuan, ${ }^{\mathrm{a}}$ Nan Li, ${ }^{\mathrm{a}}{ }^{\mathrm{R}}$ R. Bruce King* ${ }^{\mathrm{b}}$ \\ ${ }^{a}$ State Key Laboratory of Explosion Science and Technology, School of Mechatronical \\ Engineering, Beijing Institute of Technology, Beijing, 100081, P. R. China \\ ${ }^{b}$ Department of Chemistry and Center for Computational Chemistry, University of Georgia, \\ Athens, Georgia 30602, USA
}

\begin{abstract}
The $\mathrm{Cp}_{2} \mathrm{M}_{2} \mathrm{H}_{2}(\mathrm{CO})_{n}(\mathrm{M}=\mathrm{Ir}$, Os, Re; $n=3,2,1)$ systems, related to the experimentally known and structurally characterized permethylated derivatives $\mathrm{Cp}_{2}{ }_{2} \mathrm{M}_{2} \mathrm{H}_{2}(\mathrm{CO})_{2}\left(\mathrm{Cp}^{*}=\eta^{5}-\mathrm{Me}_{5} \mathrm{C}_{5} ; \mathrm{M}=\mathrm{Ir}\right.$, Os $)$, provide examples of binuclear structures having metal-metal bonds of formal orders ranging from zero to four as determined by the 18-electron rule. The low-energy $\mathrm{Cp}_{2} \mathrm{Ir}_{2} \mathrm{H}_{2}(\mathrm{CO})_{3}$ structures lacking a direct iridiumiridium bond necessarily have a bridging $\mathrm{CO}$ group holding together the two iridium atoms. For $\mathrm{Cp}_{2} \mathrm{Ir}_{2} \mathrm{H}_{2}(\mathrm{CO})_{2}$, low-energy unbridged structures are found corresponding to the experimental unbridged $\mathrm{Cp}_{2}{ }_{2} \mathrm{Ir}_{2} \mathrm{H}_{2}(\mathrm{CO})_{2}$ structure. However, for $\mathrm{Cp}_{2} \mathrm{Os}_{2} \mathrm{H}_{2}(\mathrm{CO})_{2}$ the lowest energy structure has two hydrogen atoms bridging the formal Os=Os double bond similar to the experimental doubly bridged $\mathrm{Cp}_{2}{ }_{2} \mathrm{Os}_{2} \mathrm{H}_{2}(\mathrm{CO})_{2}$ structure. The lowest energy structures of the monocarbonyls $\mathrm{Cp}_{2} \mathrm{M}_{2} \mathrm{H}_{2}(\mathrm{CO})$ have all three ligands $(2 \mathrm{H}+\mathrm{CO})$ bridging a central metal-metal bond. The $\mathrm{Cp}_{2} \mathrm{Re}_{2} \mathrm{H}_{2}(\mathrm{CO})$ structures provide examples of both bridged and unbridged structures containing formal Re-Re quadruple bonds with highly bridged structures being preferred energetically.
\end{abstract}

e-mail addresses: leen04@163.com (N. Li); rbking@ chem.uga.edu (R. B. King) 


\section{Introduction}

Hydrides of the third row transition metals are found to be more stable and correspondingly less reactive than those of the first and second row transition metals. For example, rhenium forms the unusual stable binary nonacoordinate anion $[1,2] \mathrm{ReH}_{9}{ }^{2-}$. Stable cyclopentadienylmetal polyhydrides of the third row transition metals include the mononuclear derivatives $\mathrm{Cp}^{*} \mathrm{MH}_{n}\left(\mathrm{Cp}^{*}=\eta^{5}-\mathrm{Me}_{5} \mathrm{C}_{5} ; \mathrm{M}=\mathrm{Re}\right.$ [3,4], $n=6 ; \mathrm{M}=\mathrm{Os}$ [5], $n$ $=5 ; \mathrm{M}=\operatorname{Ir}[6], n=4)$. All of these mononuclear metal hydride derives obey the 18electron rule $[7,8,9,10,11]$ The stable binuclear derivatives $\mathrm{Cp}^{*}{ }_{2} \mathrm{M}_{2} \mathrm{H}_{n}(\mathrm{M}=\operatorname{Re}[3,4], n=$ 6; $\mathrm{M}=$ Os [5], $n=4 ; \mathrm{M}=\mathrm{Ir}$ [12], $n=2$ ) also obey the 18-electron rule if the central $\mathrm{M} \equiv \mathrm{M}$ bond is regarded as a formal triple bond. In addition the mononuclear cyclopentadienylmetal carbonyl hydrides $\mathrm{CpW}(\mathrm{CO})_{3} \mathrm{H}$ [13], $\mathrm{CpRe}(\mathrm{CO})_{2} \mathrm{H}_{2}$ [14], $\mathrm{CpOs}(\mathrm{CO})_{2} \mathrm{H}$ [15], and $\mathrm{Cp}^{*} \mathrm{Os}(\mathrm{CO}) \mathrm{H}_{3}[16]$ are all isolable compounds, which are more stable and thus correspondingly less reactive than their analogues containing first and second row transition metals.

Two binuclear cyclopentadienylmetal carbonyl hydrides are known containing the third row transition metals, namely $\mathrm{Cp}^{*}{ }_{2} \mathrm{Os}_{2}(\mathrm{CO})_{2} \mathrm{H}_{2}$ [16] and $\mathrm{Cp}{ }_{2} \mathrm{Ir}_{2}(\mathrm{CO})_{2} \mathrm{H}_{2}$ [17]. Of interest are the same molecular formulas for both species even though osmium has eight valence electrons and iridium has nine valence electrons. The structures of both species have been partially determined by X-ray crystallography but the hydrogen atoms could not be located. In order to clarify the nature of these species and related binuclear cyclopentadienylmetal carbonyl hydrides, the structures and thermochemistry of the complete series of $\mathrm{Cp}_{2} \mathrm{M}_{2}(\mathrm{CO})_{n} \mathrm{H}_{2}(\mathrm{M}=\mathrm{Re}$, Os, Ir; $n=3,2,1)$ have been investigated using density functional theory. The metal-metal interactions in these binuclear cyclopentadienylmetal carbonyl hydrides are of particular interest since species with formal metal-metal bond orders ranging from 0 to 4 are found.

\section{Theoretical Methods}

Electron correlation effects were considered by employing density functional theory (DFT) methods, which have been regard as a practical and effective computational tool, especially for organometallic compounds $[18,19,20,21,22,23,24]$. In our study, three DFT methods were used, namely BP86, MPW1PW91, and M06-L. The BP86 method is a pure DFT method combining Becke's 1988 exchange functional (B) with Perdew's 1986 gradient-corrected correlation functional (P86) [25,26]. The MPW1PW91 method combines the modified Perdew-Wang exchange functional with the Perdew-Wang 91 gradient-correlation functional [27]. The M06-L method developed by Zhao and Truhlar 
[28] is based on the M05 [29] and VSXC [30] functionals. The MPW1PW91 functional is better than the first-generation functionals for second- and third-row transition metal systems [31], whereas the BP86 method provides more accurate vibrational frequencies $[32,33]$. In addition, a recent detailed study of 35 different DFT methods suggests that the M06-L method coupled with suitable basis sets predicts structures very consistent with experiment for transition metal organometallic and carbonyl derivatives [34]. For this reason, only the M06-L results (geometries, energies, and interatomic distances) are discussed in the text unless specifically noted otherwise.

The geometries of the $\mathrm{Cp}_{2} \mathrm{M}_{2} \mathrm{H}_{2}(\mathrm{CO})_{n}(\mathrm{M}=\mathrm{Re}$, Os, Ir; $n=3,2,1)$ structures were fully optimized using the two selected DFT methods with DZP and SDD basis sets for the light atoms and heavy atoms, respectively. Vibrational frequencies were determined by evaluating analytically the second derivatives of the energy with respect to the nuclear coordinates. Our DZP basis sets used for carbon, oxygen, and hydrogen add one set of pure spherical harmonic $d$ functions with orbital exponents $R_{d}(C)=0.75, R_{d}(O)=0.85$, and $\mathrm{R}_{\mathrm{d}}(\mathrm{H})=0.70$ to the standard Huzinaga-Dunning-Hay contracted DZ sets $[35,36]$. The carbon and oxygen basis sets are designated as $(9 \mathrm{~s} 5 \mathrm{p} 1 \mathrm{~d} / 4 \mathrm{~s} 2 \mathrm{p} 1 \mathrm{~d})$, whereas the hydrogen basis set is designated as $(4 \mathrm{~s} 1 \mathrm{p} / 2 \mathrm{~s} 1 \mathrm{p})$. The Stuttgart-Dresden double- $\zeta$ (SDD) effective core potential (ECP) basis set was used for the rhenium, osmium, and iridium atoms $[37,38]$.

All of the computations were carried out using the Gaussian 09 program package [39]. A large number of stable structures were predicted by these three methods. If not specifically mentioned, only those structures with energies within $\sim 10 \mathrm{kcal} \cdot \mathrm{mol}^{-1}$ by the M06-L method are discussed in the text. A summary of the vibrational frequencies and structure data calculated by M06-L, MPW1PW91 and BP86 method is given in the Supporting Information.

\section{Results}

All of the structures discussed in this section have two pentahapto $\eta^{5}$-Cp rings bonded to the metal atom and are genuine minima without any imaginary vibrational frequencies. The structures are ordered based on the energies predicted by the M06-L method.

\subsection{The $\mathrm{Cp}_{2} \mathrm{Ir}_{2} \mathrm{H}_{2}(\mathrm{CO})_{n}(n=3,2,1)$ structures}

3.1.1 $\mathrm{Cp}_{2} \mathrm{Ir}_{2} \mathrm{H}_{2}(\mathrm{CO})_{3}$. Seven low-energy structures were found for $\mathrm{Cp}_{2} \mathrm{Ir}_{2} \mathrm{H}_{2}(\mathrm{CO})_{3}$ (Figure 1). Five of these seven structures, namely Ir-3CO-2S through Ir-3CO-6S, are related structures having non-bonding $\mathrm{Ir}^{\cdots \cdots} \mathrm{Ir}$ distances ranging from 3.63 to $3.76 \AA$ and closely spaced energies ranging from 1.2 to $3.9 \mathrm{kcal} \cdot \mathrm{mol}^{-1}$ above $\mathbf{I r - 3 C O - 1 S}$. Thus the two 
halves of each of these five molecules are held together solely by the bridging $\mathrm{CO}$ group. All five structures have one terminal hydrogen atom and one terminal $\mathrm{CO}$ group on each metal atom and differ only in the relative locations of the ligands.
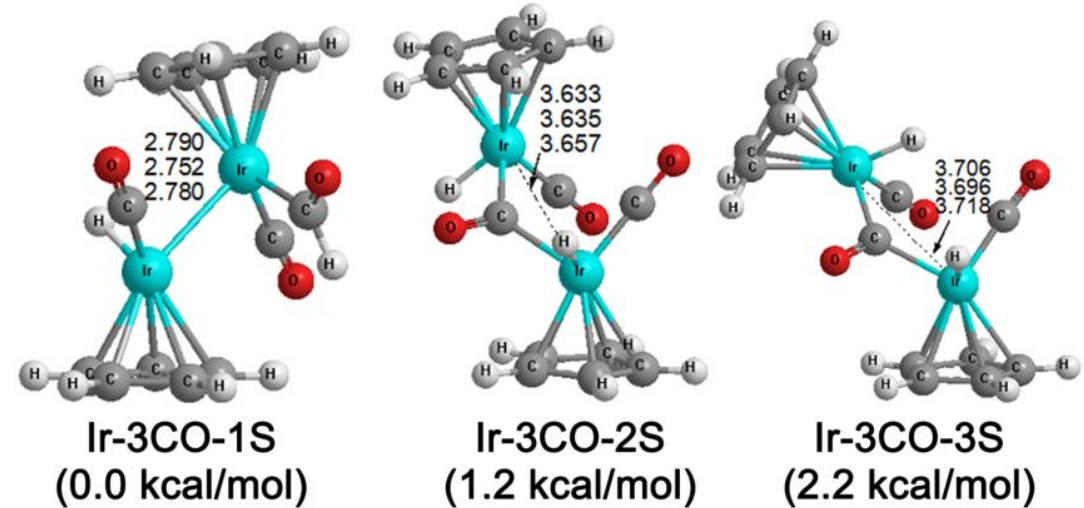

Ir-3CO-3S

(1.2 kcal $/ \mathrm{mol})$
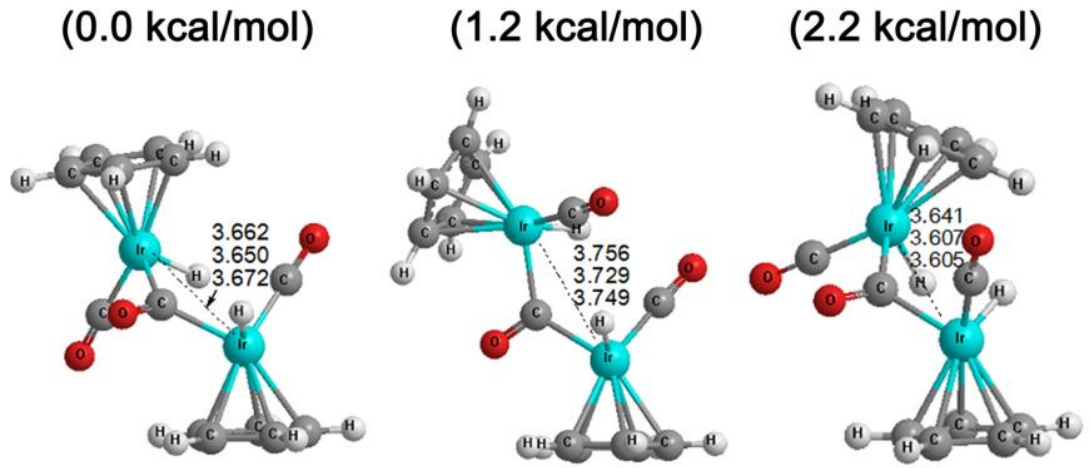

Ir-3CO-4S

Ir-3CO-5S

$(2.4 \mathrm{kcal} / \mathrm{mol})$

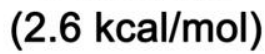

Ir-3CO-6S

(3.9 $\mathrm{kcal} / \mathrm{mol})$

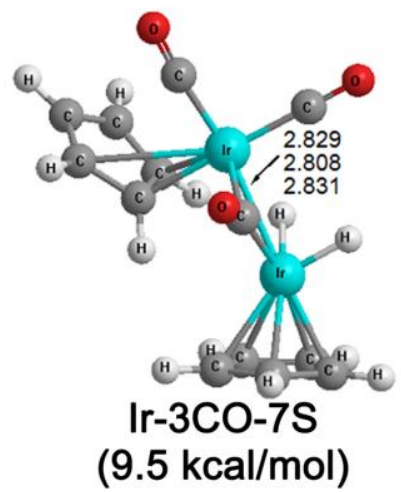

Figure 1. Optimized geometries of the seven $\mathrm{Cp}_{2} \mathrm{Ir}_{2} \mathrm{H}_{2}(\mathrm{CO})_{3}$ structures including the Ir-Ir distances and relative energies.

The remaining two low-energy $\mathrm{Cp}_{2} \mathrm{Ir}_{2} \mathrm{H}_{2}(\mathrm{CO})_{3}$ structures Ir-3CO-1S and Ir-3CO-7S are geometrically quite different from the five structures Ir-3CO-2S through Ir-3CO-6S. Structure Ir-3CO-1S is the lowest energy $\mathrm{Cp}_{2} \operatorname{Ir}_{2} \mathrm{H}_{2}(\mathrm{CO})_{3}$ structure. In Ir-3CO-1S one iridium atom bears a terminal $\mathrm{CO}$ group and a terminal hydrogen atom whereas the other iridium atom bears a terminal $\mathrm{CO}$ group and a terminal formyl group. Structure Ir-3CO-7S, lying $9.5 \mathrm{kcal} \cdot \mathrm{mol}^{-1}$ in energy above Ir-3CO-1S, is unusual since 
one of the $\mathrm{Cp}$ rings has "slipped" to become a trihapto ligand rather than the usual pentahapto ligand. The iridium atom bearing the trihapto Cp ring in $\mathbf{I r - 3 C O - 7 S}$ is bonded to terminal $\mathrm{CO}$ groups whereas the other iridium atom is bonded to a terminal hydrogen atom. The third $\mathrm{CO}$ group in Ir-3CO-7S bridges the two metal atoms. The Ir-Ir distances of $\sim 2.8 \AA$ in Ir-3CO-1S and Ir-3CO-7S can correspond to the formal single bonds required to give each iridium atom the favored 18 -electron configuration.

3.1.2 $\mathrm{Cp}_{2} \mathrm{Ir}_{2} \mathrm{H}_{2}(\mathrm{CO})_{2}$. Nine low-energy singlet $\mathrm{Cp}_{2} \mathrm{Ir}_{2} \mathrm{H}_{2}(\mathrm{CO})_{2}$ structures having energies within $9 \mathrm{kcal} \cdot \mathrm{mol}^{-1}$ were optimized (Figure 2). The Ir-Ir distances in all nine structures are predicted to range from 2.70 to $2.85 \AA$, consistent with formal single bonds. The global minimum Ir-2CO-1S is a $C_{2}$ trans structure with no bridging $\mathrm{CO}$ groups or hydrogen atoms. However, the $\mathrm{Cp}_{2} \mathrm{Ir}_{2} \mathrm{H}_{2}(\mathrm{CO})_{2}$ structure very close to the experimental $\mathrm{Cp}^{*}{ }_{2} \mathrm{Ir}_{2} \mathrm{H}_{2}(\mathrm{CO})_{2}\left(\mathrm{Cp}^{*}=\eta^{5}-\mathrm{Me}_{5} \mathrm{C}_{5}\right)$ structure, characterized by $\mathrm{X}$-ray crystallography, is Ir-2CO-2S, lying only $0.3 \mathrm{kcal} \cdot \mathrm{mol}^{-1}$ in energy above Ir-2CO-1S (Table 1) [17]. Thus, the predicted Ir-Ir distance in Ir-2CO-2S of 2.779 $\AA$ (M06-L), $2.740 \AA$ (MPW1PW91), or $2.769 \AA$ (BP86) is close to the Ir-Ir distance of $2.730 \AA$ for $\mathrm{Cp}^{*}{ }_{2} \mathrm{Ir}_{2} \mathrm{H}_{2}(\mathrm{CO})_{2}$ as determined by X-ray crystallography. The predicted $\mathrm{Ir}-\mathrm{C}$ distances to the terminal $\mathrm{CO}$ groups in Ir-2CO-2S of $1.834 \AA$ (M06-L), $1.826 \AA$ (MPW1PW91), or $1.833 \AA$ (BP86) are close to the experimental values of 1.817 and $1.829 \AA$ for the two Ir- $\mathrm{C}$ bonds in $\mathrm{Cp}_{2}{ }_{2} \mathrm{Ir}_{2} \mathrm{H}_{2}(\mathrm{CO})_{2}$. The predicted Ir-Ir-C bond angles of $84.8^{\circ}$ (M06-L) or $86.6^{\circ}$ (MPW1PW91) or $87.7^{\circ}$ (BP86) are close to the experimental values of $85.1^{\circ}$ and $85.4^{\circ}$ for $\mathrm{Cp}_{2}{ }_{2} \mathrm{Ir}_{2} \mathrm{H}_{2}(\mathrm{CO})_{2}$. The $\mathrm{Cp}_{2} \mathrm{Ir}_{2} \mathrm{H}_{2}(\mathrm{CO})_{2}$ structures Ir-2CO-2S and $\mathbf{I r - 2 C O - 3 S}$, lying 0.3 and $2.1 \mathrm{kcal} \cdot \mathrm{mol}^{-1}$ in energy above Ir-2CO-1S, are similar to Ir-2CO-1S and to each other except for the diverse dihedrals and angles. Thus the $\mathrm{C}-\mathrm{Ir}-\mathrm{Ir}-\mathrm{C}$ dihedral angles in Ir-2CO-1S, Ir-2CO-2S, and Ir-2CO-3S are $96.6^{\circ}, 180^{\circ}$, and $92.3^{\circ}$, respectively.

The next $\mathrm{Cp}_{2} \mathrm{Ir}_{2} \mathrm{H}_{2}(\mathrm{CO})_{2}$ structure Ir-2CO-4S, lying only $4.1 \mathrm{kcal} \cdot \mathrm{mol}^{-1}$ in energy above Ir-2CO-1S, is a $C_{2 h}$ singlet structure with two hydrogen bridges and a terminal $\mathrm{CO}$ group on each iridium atom with a trans orientation of the two $\mathrm{CO}$ groups. Structure Ir-2CO-8S, lying $6.9 \mathrm{kcal} \cdot \mathrm{mol}^{-1}$ in energy above Ir-2CO-1S, is the cis isomer corresponding to Ir-2CO-4S. Structure Ir-2CO-5S, lying $4.7 \mathrm{kcal} \cdot \mathrm{mol}^{-1}$ in energy above Ir-2CO-1S, has the opposite ligand configuration of Ir-2CO-8S with two bridging CO groups and two terminal hydrogen atoms in a cis configuration. Structure Ir-2CO-9S, lying $8.8 \mathrm{kcal} \cdot \mathrm{mol}^{-1}$ in energy above Ir-2CO-1S, is the trans isomer corresponding to Ir-2CO-5S. Structure Ir-2CO-6S, lying $6.9 \mathrm{kcal} \cdot \mathrm{mol}^{-1}$ in energy above Ir-2CO-1S, has one bridging $\mathrm{CO}$ group. In Ir-2CO-6S two terminal hydrogen atoms are bonded to one of the iridium atoms and one terminal $\mathrm{CO}$ group is bonded to the other iridium atom. 

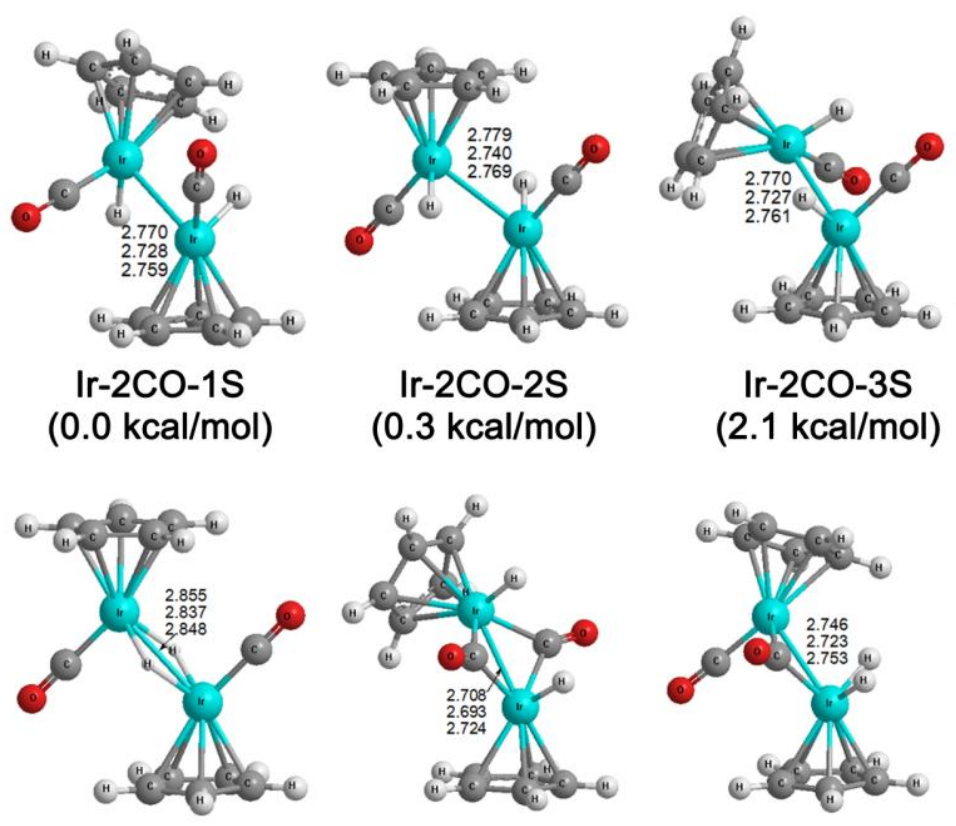

Ir-2CO-4S

$(4.1 \mathrm{kcal} / \mathrm{mol})$

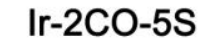

$(4.7 \mathrm{kcal} / \mathrm{mol})$
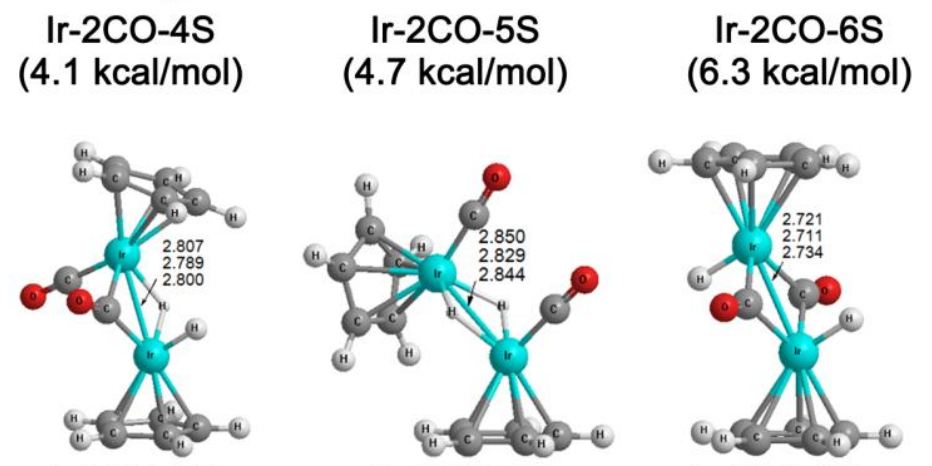

Ir-2CO-7S

$(6.4 \mathrm{kcal} / \mathrm{mol})$
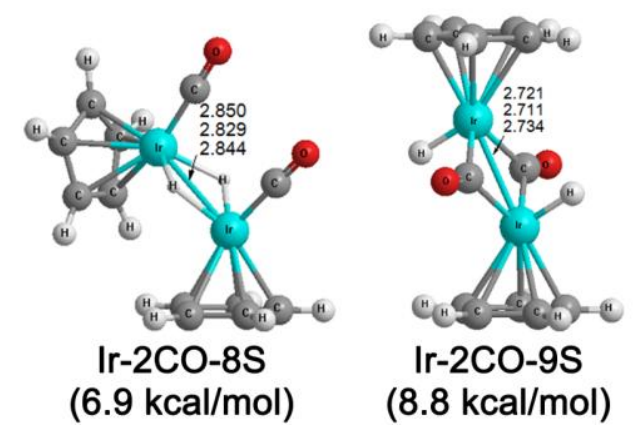

Figure 2. Optimized geometries of the nine $\mathrm{Cp}_{2} \mathrm{Ir}_{2} \mathrm{H}_{2}(\mathrm{CO})_{2}$ structures including the Ir-Ir distances and relative energies.

Table 1. Comparison of predicted geometrical parameters for the $\mathrm{Cp}_{2} \mathrm{Ir}_{2} \mathrm{H}_{2}(\mathrm{CO})_{2}$ structure Ir-2CO-2S with the experimental values [17] for $\mathrm{Cp}^{*}{ }_{2} \mathrm{Ir}_{2} \mathrm{H}_{2}(\mathrm{CO})_{2}$ determined by X-ray crystallography.

\begin{tabular}{ccc}
\hline category & experimental & theoretical \\
\hline Ir-Ir distance & $2.730 \AA$ & $2.779 \AA(\mathrm{M} 06-\mathrm{L})$ \\
& & $2.740 \AA$ (MPW1PW91) \\
& & $2.769 \AA(\mathrm{BP} 86)$ \\
\hline $\mathrm{C}-\mathrm{Ir}(1)$ distance & $1.817 \AA$ & $1.834 \AA(\mathrm{M} 06-\mathrm{L})$ \\
$\mathrm{C}-\mathrm{Ir}(2)$ distance & $1.829 \AA$ & $1.826 \AA(\mathrm{MPW} 1 \mathrm{PW} 91)$ \\
& & $1.833 \AA(\mathrm{BP} 6)$ \\
\hline Ir-Ir-C(1) angles ${ }^{\mathrm{a}}$ & $85.1^{\circ}$ & $84.8^{\circ}(\mathrm{M} 06-\mathrm{L})$ \\
Ir-Ir-C(2) angles $^{\mathrm{a}}$ & $85.4^{\circ}$ & $86.6^{\circ}(\mathrm{MPW} 1 \mathrm{PW} 91)$ \\
& & $87.7^{\circ}(\mathrm{BP} 86)$ \\
\hline
\end{tabular}

\footnotetext{
${ }^{\mathbf{a}} \operatorname{Ir}(1)$ refers to the upper iridium atom and Ir (2) means the bottom iridium atom in Figure 2.
} 
The final low-energy $\mathrm{Cp}_{2} \mathrm{Ir}_{2} \mathrm{H}_{2}(\mathrm{CO})_{2}$ structure Ir-2CO-7S, lying $6.4 \mathrm{kcal} \cdot \mathrm{mol}^{-1}$ in energy above Ir-2CO-1S, is a doubly bridged structure with a bridging $\mathrm{CO}$ group and a bridging hydrogen atom. One iridium atom bears a terminal hydrogen atom whereas the other iridium atom bears a terminal $\mathrm{CO}$ group with the terminal ligands in a trans configuration. The hydrogen bridge is slightly unsymmetrical with $\mathrm{Ir}-\mathrm{H}$ distances of 1.76 and $1.80 \AA$. The bridging $\mathrm{CO}$ group is considerably more unsymmetrical with Ir-C distances of 1.92 and $2.21 \AA$, respectively. The Ir-Ir distance in Ir-2CO-7S of $2.807 \AA$ (M06-L) corresponds to a formal single bond, thereby giving each iridium atom the favored 18-electron configuration.

3.1.3 $\mathrm{Cp}_{2} \mathrm{Ir}_{2} \mathrm{H}_{2}(\mathrm{CO})$. Six singlet $\mathrm{Cp}_{2} \mathrm{Ir}_{2} \mathrm{H}_{2}(\mathrm{CO})$ structures (Figure 3) were optimized. The Ir-Ir distances in these $\mathrm{Cp}_{2} \mathrm{Ir}_{2} \mathrm{H}_{2}(\mathrm{CO})$ structures are predicted to range from $\sim 2.50$ to $2.62 \AA$, consistent with $\mathrm{Ir}=\mathrm{Ir}$ double bonds. The lowest energy $\mathrm{Cp}_{2} \mathrm{Ir}_{2} \mathrm{H}_{2}(\mathrm{CO})$ structure is a triply bridged $C_{2 v}$ structure Ir-1CO-1S with one bridging carbonyl group, two bridging hydrogen atoms with $\mathrm{Ir}-\mathrm{H}$ distances of $1.799 \AA$, and cyclopentadienyl rings as the only terminal group bonded to each iridium atom. The three bridging groups in Ir-1CO-1S combined with the formal Ir=Ir double bond gives each iridium atom the favored 18electron configuration.

The $\mathrm{Cp}_{2} \mathrm{Ir}_{2} \mathrm{H}_{2}(\mathrm{CO})$ structure Ir-1CO-2S, lying only $4.1 \mathrm{kcal} \cdot \mathrm{mol}^{-1}$ in energy above Ir-1CO-1S, has trans stereochemistry with one bridging hydrogen, one terminal hydrogen, and one terminal carbonyl group. The $\mathrm{Cp}_{2} \mathrm{Ir}_{2} \mathrm{H}_{2}(\mathrm{CO})$ structure Ir-1CO-3S, lying $7.3 \mathrm{kcal} \cdot \mathrm{mol}^{-1}$ in energy above Ir-1CO-1S, is the corresponding cis isomer. Another stable singlet $\mathrm{Cp}_{2} \mathrm{Ir}_{2} \mathrm{H}_{2}(\mathrm{CO})$ structure Ir-1CO-4S, lying $8.3 \mathrm{kcal} \cdot \mathrm{mol}^{-1}$ in energy above Ir-1CO-1S, has one bridging carbonyl, one bridging hydrogen, and one terminal hydrogen. The formal double bond suggested by the $\mathrm{Ir}=\mathrm{Ir}$ distances of $\sim 2.6 \AA$ in each of these three structures gives each iridium atom the favored 18-electron configuration.

The lowest energy unbridged $\mathrm{Cp}_{2} \mathrm{Ir}_{2} \mathrm{H}_{2}(\mathrm{CO})$ structures Ir-1CO-5S and Ir-1CO-6S, lying 11.0 and $15.2 \mathrm{kcal} \cdot \mathrm{mol}^{-1}$ in energy above Ir-1CO-1S, respectively, are a trans/cis isomer pair having two terminal hydrogen atoms on one iridium atom and the terminal $\mathrm{CO}$ group on the other iridium atom. The less hindered trans isomer Ir-1CO-5S is the lower energy of these two structures. The Ir=Ir distances of $\sim 2.5 \AA$ are $\sim 0.1 \AA$ shorter than those in the bridged $\mathrm{Cp}_{2} \mathrm{Ir}_{2} \mathrm{H}_{2}(\mathrm{CO})$ structures. However, they still can be interpreted as the formal double bonds required to give each iridium atom the favored 18-electron configuration. 

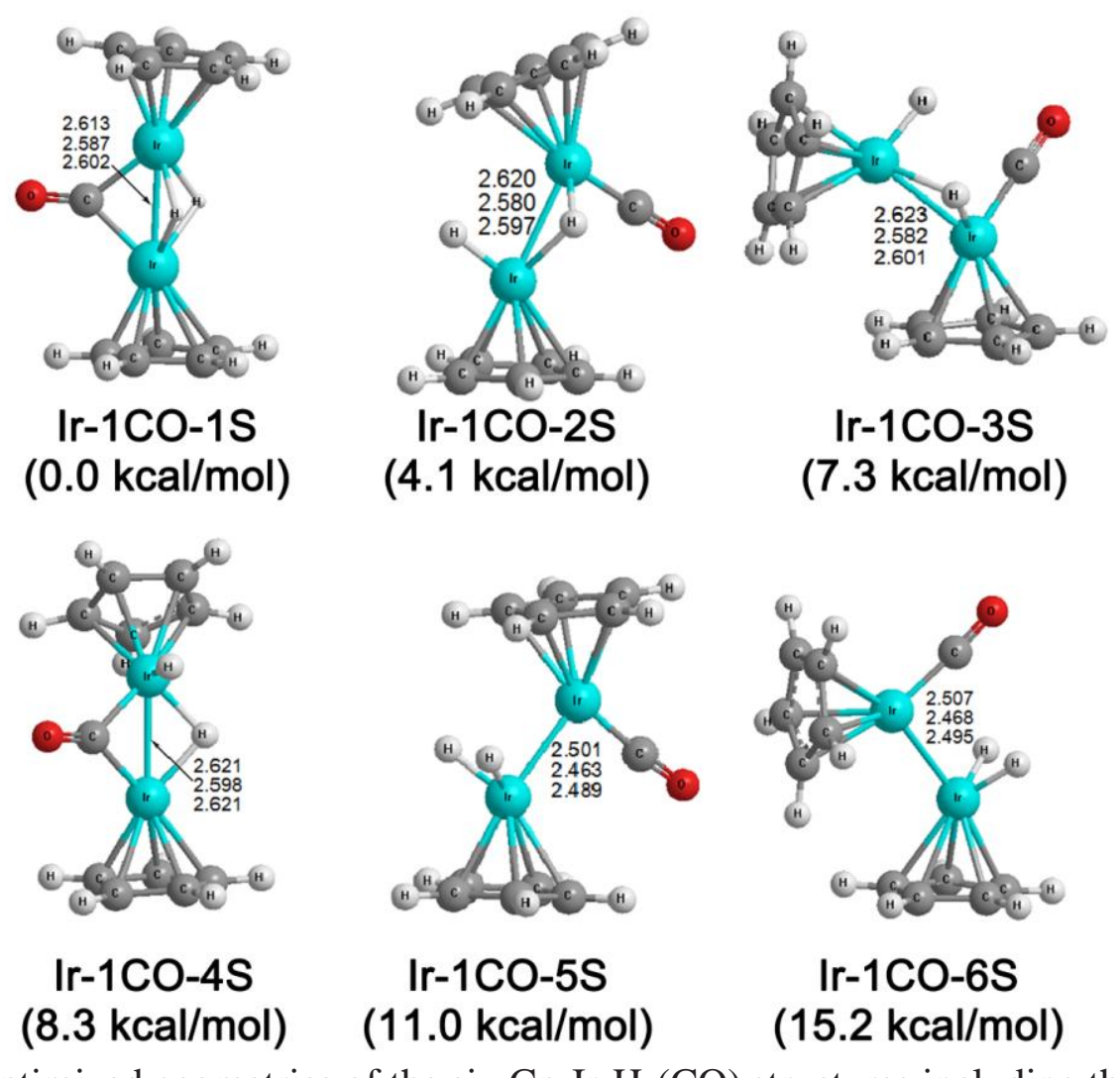

Figure 3. Optimized geometries of the six $\mathrm{Cp}_{2} \mathrm{Ir}_{2} \mathrm{H}_{2}(\mathrm{CO})$ structures including the $\mathrm{Ir}-\mathrm{Ir}$ distances and relative energies.

\subsection{The $\mathrm{Cp}_{2} \mathrm{Os}_{2} \mathrm{H}_{2}(\mathrm{CO})_{n}(n=3,2,1)$ structures}

3.2.1 $\mathrm{Cp}_{2} \mathrm{Os}_{2} \mathrm{H}_{2}(\mathrm{CO})_{3}$. Ten singlet $\mathrm{Cp}_{2} \mathrm{Os}_{2} \mathrm{H}_{2}(\mathrm{CO})_{3}$ structures were found within $12 \mathrm{kcal} \cdot \mathrm{mol}^{-1}$ of the lowest energy structures (Figure 4). All ten structures contain a OsOs single bond, typically of length $\sim 2.9 \AA$. The lowest energy $\mathrm{Cp}_{2} \mathrm{Os}_{2} \mathrm{H}_{2}(\mathrm{CO})_{3}$ structure Os-3CO-1S, as well as the higher energy structures Os-2CO-2S and Os-2CO-6S, lying 1.9 and $5.4 \mathrm{kcal} \mathrm{mol}^{-1}$ in energy above Os-3CO-1S, respectively, are unbridged structures. Two terminal CO groups are bonded to one osmium atom. The third terminal $\mathrm{CO}$ group and the two terminal hydrogen atoms are bonded to the other osmium atom. These three $\mathrm{Cp}_{2} \mathrm{Os}_{2} \mathrm{H}_{2}(\mathrm{CO})_{3}$ structures differ only in the ligand orientations. The two lower energy of these three structures, namely Os-3CO-1S and Os-3CO-2S, have a trans orientation of the $\mathrm{Cp}$ rings whereas the higher energy structure Os-3CO-6S has a slightly more sterically hindered cis orientation of the $\mathrm{Cp}$ rings.

The next two $\mathrm{Cp}_{2} \mathrm{Os}_{2} \mathrm{H}_{2}(\mathrm{CO})_{3}$ structures Os-3CO-3S and Os-3CO-4S are nearly degenerate in energy, lying 2.4 and $2.7 \mathrm{kcal} \cdot \mathrm{mol}^{-1}$ above Os-3CO-1S. Each structure has a trans orientation of the $\mathrm{Cp}$ ligands, one bridging $\mathrm{CO}$ group, as well as a terminal $\mathrm{CO}$ group and a terminal hydrogen bonded to each osmium atom. These structures differ only 
in the orientations of the ligands. Considering the Os-Os distances of $\sim 2.84 \AA$ as formal single bonds gives each osmium atom the favored 18-electron configuration. The $\mathrm{Cp}_{2} \mathrm{Os}_{2} \mathrm{H}_{2}(\mathrm{CO})_{3}$ structure Os-3CO-7S, lying $6.2 \mathrm{kcal} \cdot \mathrm{mol}^{-1}$ in energy above Os-3CO-1S, is a closely related structure with a cis orientation of the $\mathrm{Cp}$ ligands.

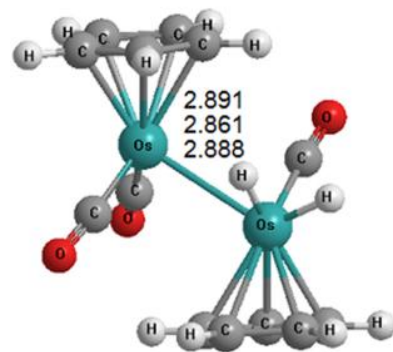

Os-3CO-1S $(0.0 \mathrm{kcal} / \mathrm{mol})$

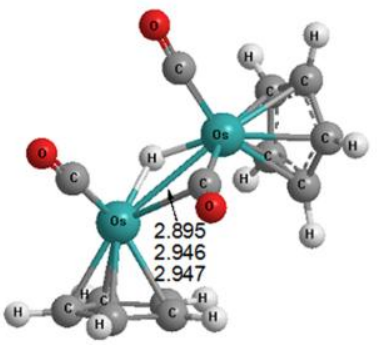

Os-3CO-5S $(4.4 \mathrm{kcal} / \mathrm{mol})$

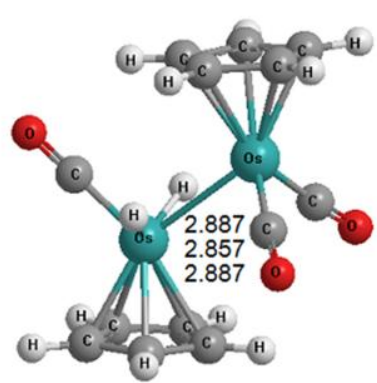

Os-3CO-2S (1.9 kcal $/ \mathrm{mol})$

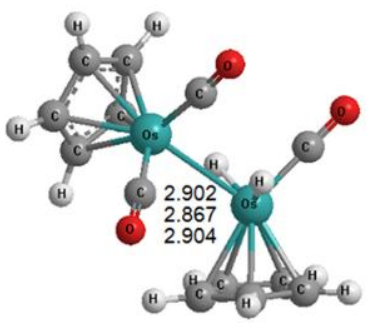

Os-3Co-6S $(5.4 \mathrm{kcal} / \mathrm{mol})$

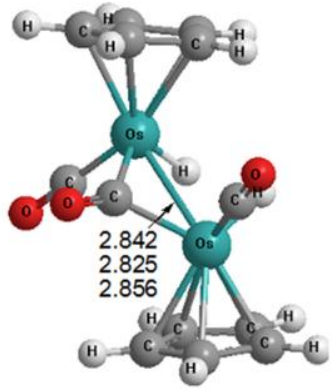

Os-3CO-3S $(2.4 \mathrm{kcal} / \mathrm{mol})$

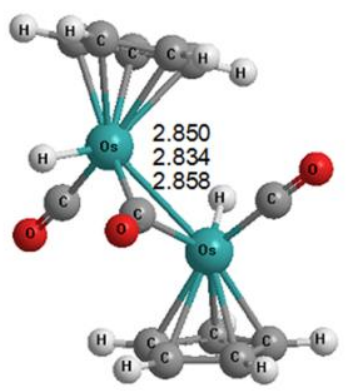

Os-3CO-4S (2.7 kcal $/ \mathrm{mol})$

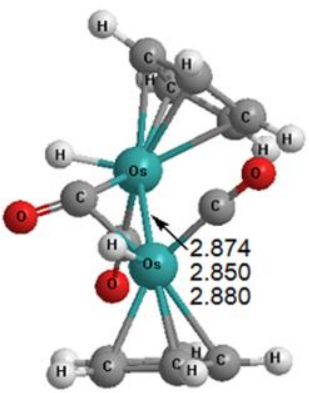

Os-3CO-7S (6.2 kcal $/ \mathrm{mol})$

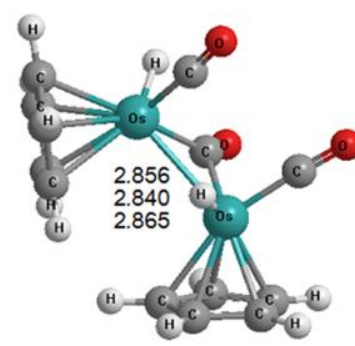

Os-3CO-8S (6.5 kcal $/ \mathrm{mol})$

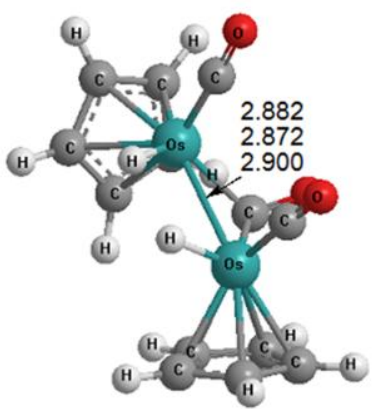

Os-3CO-9S (7.9 kcal $/ \mathrm{mol})$

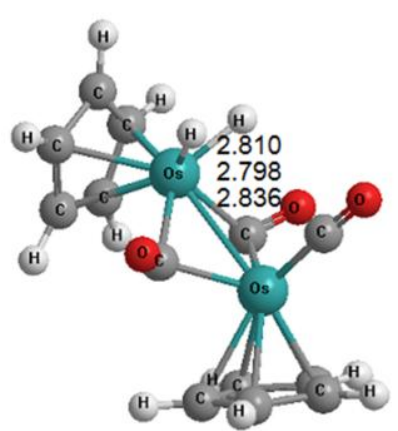

OS-3CO-10S (11.3 kcal/mol)

Figure 4. Optimized geometries of the ten $\mathrm{Cp}_{2} \mathrm{Os}_{2} \mathrm{H}_{2}(\mathrm{CO})_{3}$ structures including the Os-Os distances and relative energies.

The $\mathrm{Cp}_{2} \mathrm{Os}_{2} \mathrm{H}_{2}(\mathrm{CO})_{3}$ structure Os-3CO-5S, lying $4.4 \mathrm{kcal} \cdot \mathrm{mol}^{-1}$ in energy above Os-3CO-1S, has two terminal CO groups in a cis orientation, one terminal hydrogen 
atom, one bridging hydrogen atom, one bridging $\mathrm{CO}$ group, and a cis orientation of the Cp rings. The predicted Os-Os distance of $2.895 \AA$ (M06-L) is somewhat longer than the lower energy $\mathrm{Cp}_{2} \mathrm{Os}_{2} \mathrm{H}_{2}(\mathrm{CO})_{3}$ isomers because of the bridging hydrogen atom. It can be interpreted as the formal single bond required to give each osmium atom the favored 18-electron configuration.

The three $\mathrm{Cp}_{2} \mathrm{Os}_{2} \mathrm{H}_{2}(\mathrm{CO})_{3}$ structures Os-3CO-7S, Os-3CO-8S, and Os-3CO-9S, lying 6.2, 6.5, and $7.9 \mathrm{kcal} \cdot \mathrm{mol}^{-1}$ in energy above Os-3CO-1S, respectively, are very similar with one bridging $\mathrm{CO}$ group as well as a terminal hydrogen atom and a terminal $\mathrm{CO}$ group bonded to each osmium atom. The $\mathrm{Cp}$ rings in all three structures have cis orientations and the Os-Os distances of $\sim 2.85 \AA$ to $\sim 2.89 \AA$ suggest formal single bonds.

The last singlet $\mathrm{Cp}_{2} \mathrm{Os}_{2} \mathrm{H}_{2}(\mathrm{CO})_{3}$ structure Os-3CO-10S, lying $11.3 \mathrm{kcal} / \mathrm{mol}$ in energy above Os-3CO-1S, has two bridging $\mathrm{CO}$ groups and a cis orientation of the $\mathrm{Cp}$ rings. One osmium atom is bonded to a terminal $\mathrm{CO}$ group. The other osmium atom is bonded to two terminal hydrogen atoms with $1.628 \AA$ Os-H distances.

3.2.2. $\mathrm{Cp}_{2} \mathrm{Os}_{2} \mathrm{H}_{2}(\mathrm{CO})_{2}$. Three structures were found for $\mathrm{Cp}_{2} \mathrm{Os}_{2} \mathrm{H}_{2}(\mathrm{CO})_{2}$ within $10 \mathrm{kcal} \cdot \mathrm{mol}^{-1}$ of the global minimum (Figure 5). The lowest energy $\mathrm{Cp}_{2} \mathrm{Os}_{2} \mathrm{H}_{2}(\mathrm{CO})_{2}$ structure Os-2CO-1S is a $C_{2 h}$ structure with two bridging hydrogen atoms and two terminal CO groups with a trans orientation. Structure Os-2CO-1S is very close to the experimental $\mathrm{Cp}^{*}{ }_{2} \mathrm{Os}_{2} \mathrm{H}_{2}(\mathrm{CO})_{2}$ structure $\left(\mathrm{Cp}^{*}=\eta^{5}-\mathrm{Me}_{5} \mathrm{C}_{5}\right)$, structurally characterized by single-crystal X-ray crystallography (Table 2) [16]. The predicted Os=Os distance in Os-2CO-1S of $2.710 \AA$ (M06-L), $2.675 \AA$ (MPW1PW91) or $2.688 \AA$ (BP86) is close to the experimental value of $2.677 \AA$ for $\mathrm{Cp}^{*}{ }_{2} \mathrm{Os}_{2} \mathrm{H}_{2}(\mathrm{CO})_{2}$. The predicted Os-H distances in Os-2CO-1S are all the same at $1.817 \AA$ (M06-L), $1.802 \AA$ (MPW1PW91), or $1.814 \AA$ (BP86). The hydrogen atoms were not found in the crystal structure of $\mathrm{Cp}^{*}{ }_{2} \mathrm{Os}_{2} \mathrm{H}_{2}(\mathrm{CO})_{2}$. The predicted Os-Os-C angles of $92.7^{\circ}$ (M06-L), 93.8 (MPW1PW91), or 94.4 ${ }^{\circ}$ (BP86) are close to the experimental value of $96.2^{\circ}$. The $\mathrm{Cp}_{2} \mathrm{Os}_{2} \mathrm{H}_{2}(\mathrm{CO})_{2}$ structure Os-2CO-2S, lying $3.8 \mathrm{kcal} \cdot \mathrm{mol}^{-1}$ in energy above Os-2CO-1S is the cis isomer corresponding to Os-2CO-1S.

The next $\mathrm{Cp}_{2} \mathrm{Os}_{2} \mathrm{H}_{2}(\mathrm{CO})_{2}$ structure Os-2CO-3S, lying $9.0 \mathrm{kcal} \cdot \mathrm{mol}^{-1}$ in energy above Os-2CO-1S, has only a single hydrogen bridge. Thus one osmium atom in Os-2CO-3S is bonded to a terminal hydrogen and a terminal CO group whereas the other osmium atom is bonded only to a terminal $\mathrm{CO}$ group. The bridging hydrogen atom in Os-2CO-3S is slightly unsymmetrical with Os-H distances of 1.797 and $1.832 \AA$. The Os-Os double bond length of $2.695 \AA$ (M06-L) in Os-2CO-3S is predicted to be slightly 
shorter than that in Os-2CO-1S but likewise can correspond to the formal double bond required to give each of the two osmium atoms the favored 18-electron configuration.

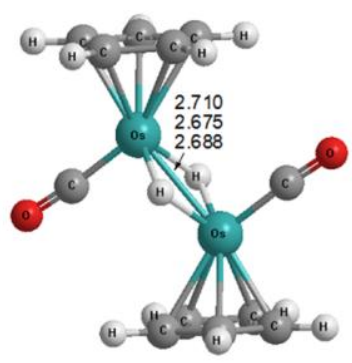

Os-2CO-1S $(0.0 \mathrm{kcal} / \mathrm{mol})$

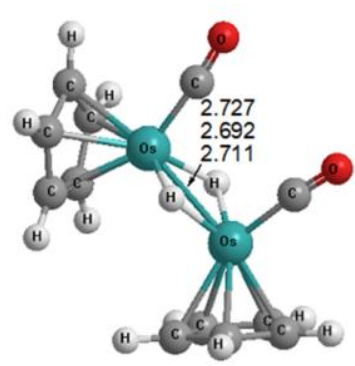

Os-2CO-2S

$(3.8 \mathrm{kcal} / \mathrm{mol})$

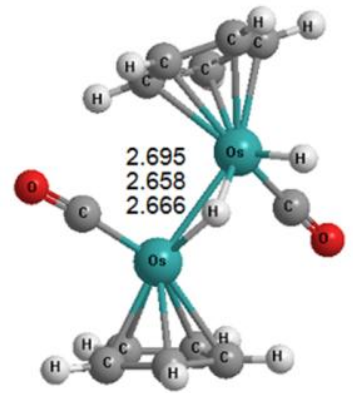

Os-2CO-3S

$(9.0 \mathrm{kcal} / \mathrm{mol})$

Figure 5. Optimized geometries of the three $\mathrm{Cp}_{2} \mathrm{Os}_{2} \mathrm{H}_{2}(\mathrm{CO})_{2}$ structures including the Os=Os distances and relative energies.

Table 2. Comparison of the experimental $\mathrm{Cp}^{*}{ }_{2} \mathrm{Os}_{2} \mathrm{H}_{2}(\mathrm{CO})_{2}$ structure with the predicted $\mathrm{Cp}_{2} \mathrm{Os}_{2} \mathrm{H}_{2}(\mathrm{CO})_{2}$ structure Os-2CO-1S.

\begin{tabular}{ccc}
\hline & Experimental & Predicted $\mathrm{Cp}_{2} \mathrm{Os}_{2} \mathrm{H}_{2}(\mathrm{CO})_{2}$ \\
& $\mathrm{Cp}_{2}{ }_{2} \mathrm{Os}_{2} \mathrm{H}_{2}(\mathrm{CO})_{2}$ structure & structure Os-2CO-1S \\
\hline Os-Os distance & $2.677 \AA$ & $2.710 \AA(\mathrm{M} 06-\mathrm{L})$ \\
& & $2.675 \AA(\mathrm{MPW} 1 \mathrm{PW} 91)$ \\
& & $2.688 \AA(\mathrm{BP} 86)$ \\
\hline Os-C distance & $1.833 \AA$ & $1.855 \AA(\mathrm{M} 06-\mathrm{L})$ \\
& & $1.849 \AA(\mathrm{MPW} 1 \mathrm{PW} 91)$ \\
& & $1.854 \AA(\mathrm{BP} 86)$ \\
\hline Os-Os-C angles & $96.2^{\circ}$ & $92.7^{\circ}(\mathrm{M} 06-\mathrm{L})$ \\
& & $93.8^{\circ}(\mathrm{MPW} 1 \mathrm{PW} 1)$ \\
& & $94.4^{\circ}(\mathrm{BP} 86)$ \\
\hline
\end{tabular}

3.2.3 $\mathrm{Cp}_{2} \mathrm{Os}_{2} \mathrm{H}_{2}(\mathrm{CO})$. Two singlet $\mathrm{Cp}_{2} \mathrm{Os}_{2} \mathrm{H}_{2}(\mathrm{CO})$ structures were found (Figure 6). The lowest energy structure Os-1CO-1S is a triply bridged $C_{2 v}$ structure with one bridging $\mathrm{CO}$ group and two bridging hydrogen atoms. The equivalent $\mathrm{Os}-\mathrm{H}-\mathrm{Os}$ angles are $86.0^{\circ}$. The Os- $\mathrm{C}$ distances to the bridging carbonyl group are $2.048 \AA$ and the Os- $\mathrm{H}$ distances to the bridging hydrogen atoms are $1.825 \AA$. The predicted Os $\equiv$ Os distance in Os-1CO-1S of $2.490 \AA$ (M06-L), $2.455 \AA$ (MPW1PW91), or $2.472 \AA$ (BP86) can correspond to the formal triple bond required to give each osmium atom the favored 18-electron configuration. 

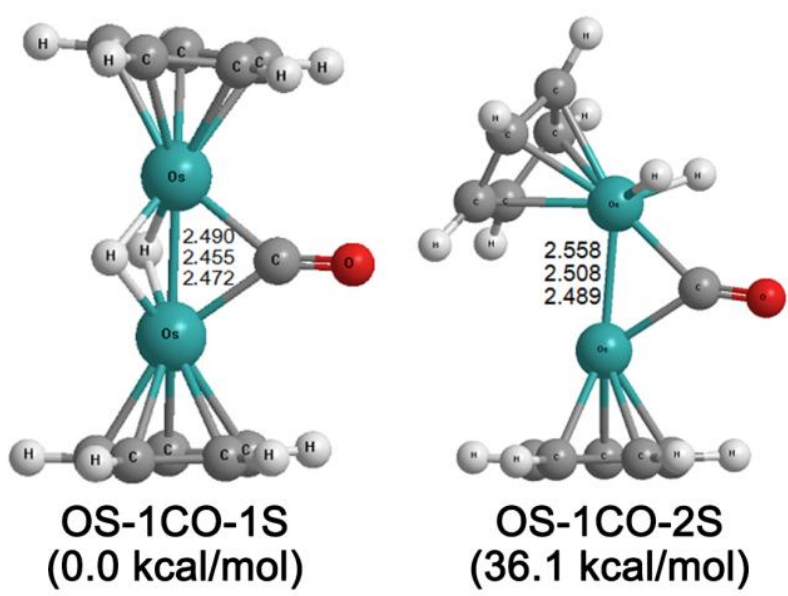

Figure 6. Optimized geometries of the two $\mathrm{Cp}_{2} \mathrm{Os}_{2} \mathrm{H}_{2}(\mathrm{CO})$ structures including the Os $\equiv$ Os distances and relative energies.

The $\mathrm{Cp}_{2} \mathrm{Os}_{2} \mathrm{H}_{2}(\mathrm{CO})$ structure Os-1CO-1S appears to be relatively favorable since the next structure in terms of energy, namely Os-1CO-2S, lies $36.1 \mathrm{kcal} / \mathrm{mol}$ (M06-L) above Os-1CO-1S. Structure Os-1CO-2S has a bridging CO group and two terminal hydrogen atoms bonded to one of the osmium atoms. The predicted Os $\equiv$ Os distance in Os-1CO-2S of $2.558 \AA$ (M06-L) is consistent with a formal triple bond. This gives each osmium atom in Os-1CO-2S the favored 18-electron configuration if the osmium atom bearing two hydrogen atoms has a formal positive charge balanced by a formal negative charge on the other osmium atom.

\subsection{The $\mathrm{Cp}_{2} \operatorname{Re}_{2} \mathrm{H}_{2}(\mathrm{CO})_{n}(n=3,2,1)$ structures}

3.3.1 $\mathrm{Cp}_{2} \mathrm{Re}_{2} \mathrm{H}_{2}(\mathrm{CO})_{3}$. Five singlet state low-energy $\mathrm{Cp}_{2} \mathrm{Re}_{2} \mathrm{H}_{2}(\mathrm{CO})_{3}$ structures were optimized (Figure 7). All of these $\mathrm{Cp}_{2} \mathrm{Re}_{2} \mathrm{H}_{2}(\mathrm{CO})_{3}$ structures have $\mathrm{Re}=\mathrm{Re}$ distances ranging from 2.7 to $2.8 \AA$, which may be interpreted as the formal double bonds required to give each rhenium atom the favored 18-electron configuration. The lowest energy $\mathrm{Cp}_{2} \mathrm{Re}_{2} \mathrm{H}_{2}(\mathrm{CO})_{3}$ structure Re-3CO-1S has a single hydrogen atom bridging the $\mathrm{Re}=\mathrm{Re}$ double bond of length $2.777 \AA$ (M06-L). One rhenium atom in Re-3CO-1S is bonded to the other hydrogen atom and a terminal $\mathrm{CO}$ group whereas the other rhenium atom is bonded to the remaining two terminal $\mathrm{CO}$ groups. A second $\mathrm{Cp}_{2} \mathrm{Re}_{2} \mathrm{H}_{2}(\mathrm{CO})_{3}$ structure Re-3CO-2S is essentially degenerate with Re-3CO-1S since the predicted energy separation of the two structures is only $0.1 \mathrm{kcal} \cdot \mathrm{mol}^{-1}$ suggesting a fluxional system. Structure Re-3CO-2S is geometrically similar to Re-3CO-1S except for the bond angles. 


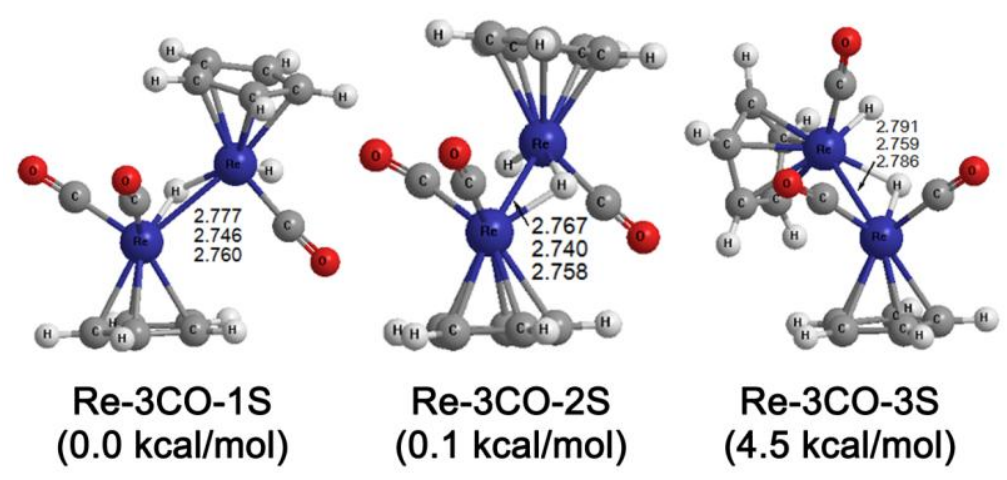

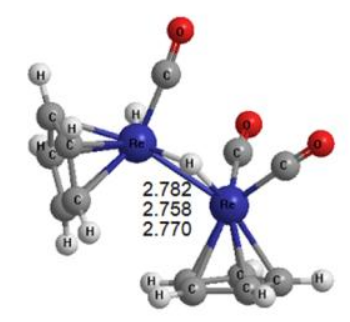

Re-3CO-4S

$(6.9 \mathrm{kcal} / \mathrm{mol})$

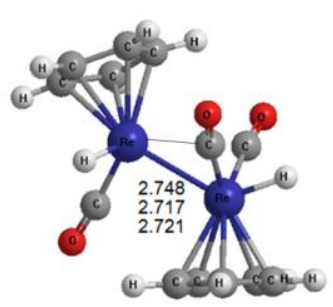

Re-3CO-5S (7.7 kcal/mol)

Figure 7. Optimized geometries of the five $\mathrm{Cp}_{2} \mathrm{Re}_{2} \mathrm{H}_{2}(\mathrm{CO})_{3}$ structures including the Re-Re distances and relative energies.

The next two $\mathrm{Cp}_{2} \mathrm{Re}_{2} \mathrm{H}_{2}(\mathrm{CO})_{3}$ structures Re-3CO-3S and Re-3CO-4S, lying 4.5 and $6.9 \mathrm{kcal} \cdot \mathrm{mol}^{-1}$ in energy above Re-3CO-1S, each have three terminal $\mathrm{CO}$ groups and one of the two hydrogen atoms as a bridge between the rhenium atoms. One of the rhenium atoms in these two structures is bonded to two terminal $\mathrm{CO}$ groups whereas the other rhenium atom is bonded to one terminal $\mathrm{CO}$ group and a terminal hydrogen atom. Interpretation of the $\operatorname{Re}=\operatorname{Re}$ distances of $\sim 2.78 \AA$ in $\mathbf{R e}-3 \mathbf{C O}-3 \mathrm{~S}$ and $\mathbf{R e - 3 C O}-\mathbf{4 S}$ as formal double bonds gives each rhenium atom the favored 18-electron configuration.

The next $\mathrm{Cp}_{2} \mathrm{Re}_{2} \mathrm{H}_{2}(\mathrm{CO})_{3}$ structure Re-3CO-5S, lying $7.7 \mathrm{kcal} / \mathrm{mol}(\mathrm{M} 06-\mathrm{L}$ ) in energy above Re-CO-1S, has a CO group and a hydrogen atom bonded to each Re atom as terminal ligands. The third $\mathrm{CO}$ group is a weakly semibridging group with a short Re-C distance of $1.935 \AA$ and a long Re-C distance of $2.635 \AA$. The $\mathrm{Re}=\mathrm{Re}$ distance of $2.748 \AA$ (M06-L) is shorter than that in other $\mathrm{Cp}_{2} \mathrm{Re}_{2} \mathrm{H}_{2}(\mathrm{CO})_{3}$ structures, possibly because of the semibridging $\mathrm{CO}$ group. However, interpreting the $\mathrm{Re}=\mathrm{Re}$ interaction in Re-3CO-5S as a formal double bond gives each rhenium atom the favored 18-electron configuration.

3.3.2 $\mathrm{Cp}_{2} \mathrm{Re}_{2} \mathrm{H}_{2}(\mathrm{CO})_{2}$. Four singlet state low-energy $\mathrm{Cp}_{2} \mathrm{Re}_{2} \mathrm{H}_{2}(\mathrm{CO})_{2}$ structures were optimized (Figure 8). All of these structures have a formal $\operatorname{Re} \equiv \operatorname{Re}$ triple bond with 
lengths of $\sim 2.48 \AA$ thereby giving each rhenium atom the favored 18-electron configuration. The lowest energy of these structures Re-2CO-1S is a $C_{2 v}$ structure having cis stereochemistry with two terminal $\eta^{5}-\mathrm{Cp}$ rings, two equivalent terminal hydrogen atoms with $\mathrm{Re}-\mathrm{H}$ distances of $1.669 \AA$, and two bridging $\mathrm{CO}$ groups with $\mathrm{Re}-\mathrm{C}$ distances of $2.063 \AA$ and $2.062 \AA$.

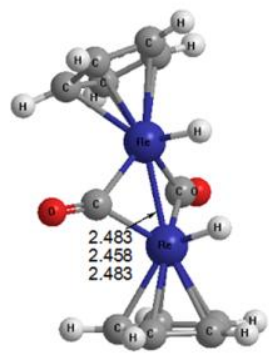

Re-2CO-1S $(0.0 \mathrm{kcal} / \mathrm{mol})$

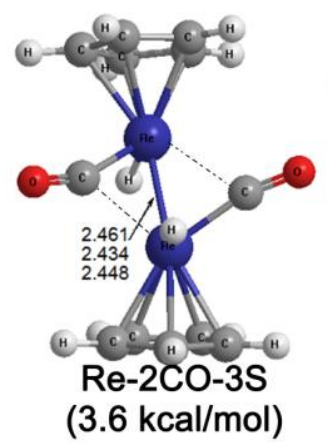

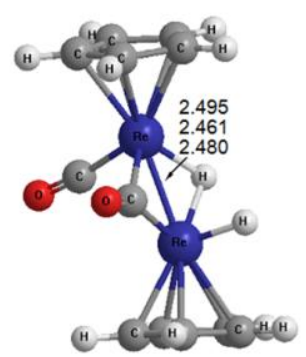

$\mathrm{Re}-2 \mathrm{CO}-2 \mathrm{~S}$ (0.6 kcal $/ \mathrm{mol}$ )

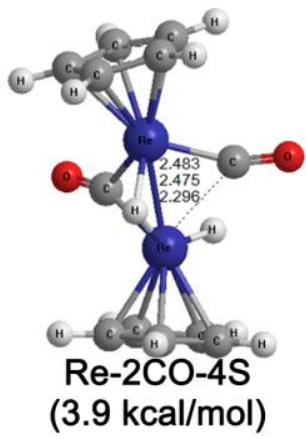

Figure 8. Optimized geometries of the four $\mathrm{Cp}_{2} \mathrm{Re}_{2} \mathrm{H}_{2}(\mathrm{CO})_{2}$ structures including the $\mathrm{Re} \equiv \mathrm{Re}$ distances and relative energies.

The second singlet $\mathrm{Cp}_{2} \mathrm{Re}_{2} \mathrm{H}_{2}(\mathrm{CO})_{2}$ structure Re-2CO-2S, lying only $0.6 \mathrm{kcal} \cdot \mathrm{mol}^{-1}(\mathrm{M} 06-\mathrm{L})$ in energy above Re-2CO-1S, has two different bridging groups, namely one $\mathrm{CO}$ group and one hydrogen atom. One rhenium atom in $\mathbf{R e - 2 C O - 2 S}$ is bonded to a terminal hydrogen atom with an Re-H distance of $1.661 \AA$ (M06-L) whereas the other rhenium atom is bonded to a terminal $\mathrm{CO}$ group with an $\mathrm{Re}-\mathrm{C}$ distance of $1.915 \AA$ with trans stereochemistry for the terminal $\mathrm{Re}-\mathrm{H}$ and $\mathrm{Re}-\mathrm{C}$ bonds. This difference in the terminal ligands on the rhenium atoms in $\mathbf{R e - 2 C O - 2 S}$ leads to asymmetry in the bridging ligands. Thus for the bridging hydrogen atom, the $\mathrm{Re}-\mathrm{H}$ distances are 1.821 and $1.880 \AA$ whereas for the bridging CO group the Re-C distances are 2.014 and $2.157 \AA$.

The $\mathrm{Cp}_{2} \mathrm{Re}_{2} \mathrm{H}_{2}(\mathrm{CO})_{2}$ structure Re-2CO-4S, lying $3.9 \mathrm{kcal} / \mathrm{mol}$ in energy above Re-2CO-1S, is closely related to $\mathbf{R e - 2 C O - 2 S}$ with one bridging CO group and one 
bridging hydrogen atom but with cis rather than trans stereochemistry of the Cp rings. However, the second $\mathrm{CO}$ group in $\mathbf{R e - 2 C O}-\mathbf{4 S}$ is a semibridging $\mathrm{CO}$ group rather than a terminal $\mathrm{CO}$ group. The two Re-C bonds to the bridging $\mathrm{CO}$ group in Re-2CO-4S are slightly unequal at 2.006 and $2.186 \AA$. However, the two Re-C bonds differ more significantly at 1.946 and $2.442 \AA$ for the semibridging $\mathrm{CO}$ group. The Re $\equiv \operatorname{Re}$ distances of $\sim 2.48 \AA$ in $\mathbf{R e - 2 C O - 1 S}$ and $\mathbf{R e - 2 C O}-\mathbf{4 S}$ are in a reasonable range for the formal triple bond required to give each rhenium atom the favored 18-electron configuration.

The $\mathrm{Cp}_{2} \mathrm{Re}_{2} \mathrm{H}_{2}(\mathrm{CO})_{2}$ structure Re-2CO-3S, lying $3.6 \mathrm{kcal} \cdot \mathrm{mol}^{-1}$ in energy above Re-2CO-1S, has two semibridging CO groups with short Re-C distances of $\sim 1.95 \AA$ and long Re-C distances of $\sim 2.3 \AA$. In addition a terminal hydrogen atom is bonded to each rhenium atom in Re-2CO-3S. The $\mathrm{Re} \equiv \mathrm{Re}$ distance of $2.461 \AA$ (M06-L), although significantly shorter than the $\mathrm{Re} \equiv \mathrm{Re}$ triple bonds in Re-2CO-1S, Re-2CO-2S, and Re-2CO-4S, can correspond to the formal triple bond required to give each rhenium atom the favored 18-electron configuration.

3.3.3 $\mathrm{Cp}_{2} \mathrm{Re}_{2} \mathrm{H}_{2}(\mathrm{CO})$. Four low-energy singlet structures were found for $\mathrm{Cp}_{2} \mathrm{Re}_{2} \mathrm{H}_{2}(\mathrm{CO})$ (Figure 9). All four structures have very short Re-Re bond distances of $\sim 2.35$ to $2.48 \AA$, which can be interpreted as the formal quadruple bonds required to give each rhenium atom the favored 18-electron configuration. The four $\mathrm{Cp}_{2} \mathrm{Re}_{2} \mathrm{H}_{2}(\mathrm{CO})$ structures differ mainly in the nature of the bridging ligands across the formal Re-Re quadruple bond. Thus in the global minimum $\mathrm{Cp}_{2} \mathrm{Re}_{2} \mathrm{H}_{2}(\mathrm{CO})$ structure Re-1CO-1S all three ligands are bridging groups with equal $\mathrm{Re}-\mathrm{C}$ and $\mathrm{Re}-\mathrm{H}$ distances, respectively, to each rhenium atom in accord with the $C_{2}$ symmetry. However, the $\mathrm{Cp}_{2} \mathrm{Re}_{2} \mathrm{H}_{2}(\mathrm{CO})$ structures Re-1CO-2S and Re-1CO-3S, lying 7.4 and $8.0 \mathrm{kcal} \cdot \mathrm{mol}^{-1}$ in energy, respectively, above Re-1CO-1S, have a bridging hydrogen atom and a bridging $\mathrm{CO}$ group leaving one terminal hydrogen atom. Structures Re-1CO-2S and Re-1CO-3S are geometrically similar except for the orientation of the $\mathrm{Cp}$ rings and the dihedral angles. The $\mathrm{Cp}_{2} \mathrm{Re}_{2} \mathrm{H}_{2}(\mathrm{CO})$ structure Re-1CO-4S, lying $10.3 \mathrm{kcal} \cdot \mathrm{mol}^{-1}$ in energy above $\mathbf{R e - 1 C O - 1 S}$, has two terminal hydrogen atoms and one semibridging $\mathrm{CO}$ group with a short $\mathrm{Re}-\mathrm{C}$ distances of $1.922 \AA$ and a long Re-C distance of $2.465 \AA$. 

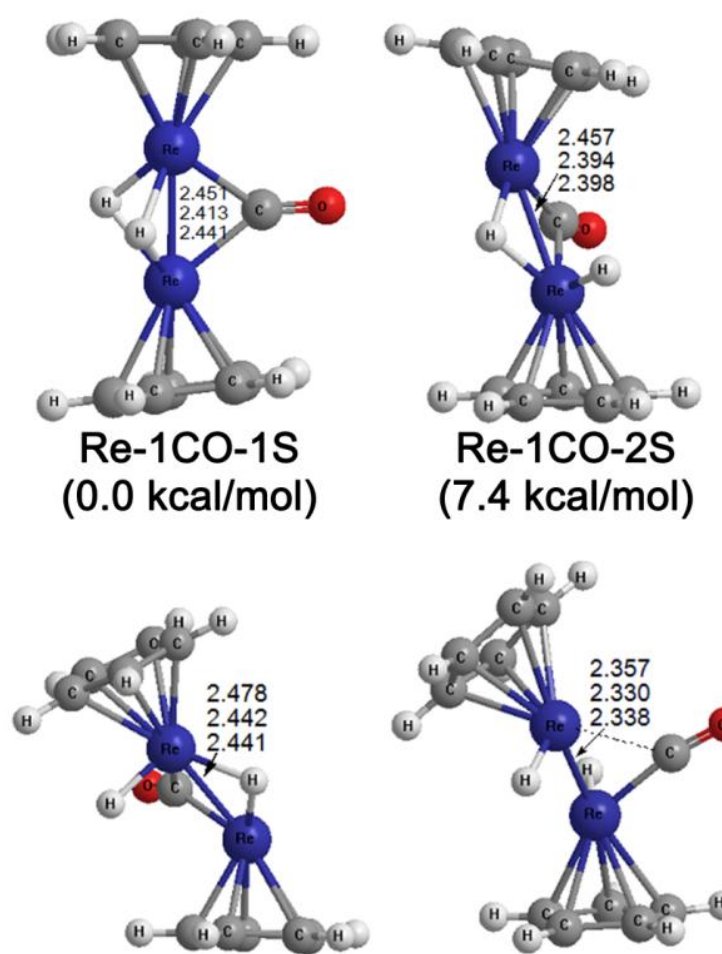

Re-1CO-3S $(8.0 \mathrm{kcal} / \mathrm{mol})$

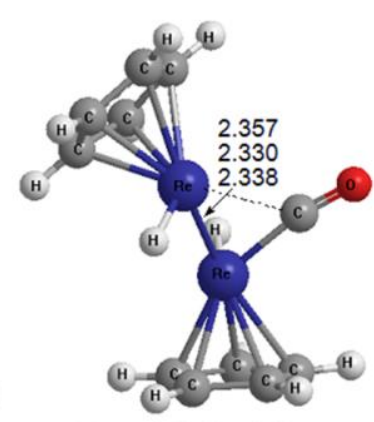

Re-1CO-4S (10.3 kcal $/ \mathrm{mol})$

Figure 9. Optimized geometries of the four $\mathrm{Cp}_{2} \mathrm{Re}_{2} \mathrm{H}_{2}(\mathrm{CO})$ structures including the Re-Re distances and relative energies.

\subsection{Thermochemistry.}

Table 3 lists the predicted $\mathrm{CO}$ dissociation energies for the reactions $\mathrm{Cp}_{2} \mathrm{M}_{2} \mathrm{H}_{2}(\mathrm{CO})_{n} \rightarrow \mathrm{Cp}_{2} \mathrm{M}_{2} \mathrm{H}_{2}(\mathrm{CO})_{n-1}+\mathrm{CO}$ based on the lowest energy structures using the three different functionals M06-L, BP86, and MPW1PW91. In general the three functionals are in good agreement, typically within $15 \%$ or less.

For the iridium system, the $\mathrm{CO}$ dissociation energy of $\mathrm{Cp}_{2} \mathrm{Ir}_{2} \mathrm{H}_{2}(\mathrm{CO})_{3}$ to $\mathrm{Cp}_{2} \mathrm{Ir}_{2} \mathrm{H}_{2}(\mathrm{CO})_{2}+\mathrm{CO}$ is rather low at $\sim 10 \mathrm{kcal} \cdot \mathrm{mol}^{-1}$ However, that of $\mathrm{Cp}_{2} \mathrm{Ir}_{2} \mathrm{H}_{2}(\mathrm{CO})_{2}$ to $\mathrm{Cp}_{2} \mathrm{Ir}_{2} \mathrm{H}_{2}(\mathrm{CO})+\mathrm{CO}$ is rather high at $\sim 47 \mathrm{kcal} \cdot \mathrm{mol}^{-1}$. This is consistent with the isolation of $\mathrm{Cp}_{2} \mathrm{Ir}_{2} \mathrm{H}_{2}(\mathrm{CO})_{2}$ as a stable molecule [17]. The dissociation reactions for the lowest energy $\mathrm{Cp}_{2} \mathrm{Os}_{2} \mathrm{H}_{2}(\mathrm{CO})_{n}$ structures are all predicted to be highly endothermic. For the osmium system the $\mathrm{CO}$ dissociation energies of both $\mathrm{Cp}_{2} \mathrm{Os}_{2} \mathrm{H}_{2}(\mathrm{CO})_{3}$ and $\mathrm{Cp}_{2} \mathrm{Os}_{3} \mathrm{H}_{2}(\mathrm{CO})_{2}$ are both relatively high at $\sim 34$ and $\sim 40 \mathrm{kcal} \cdot \mathrm{mol}^{-1}$ suggesting that either molecule could be viable. In this case the dicarbonyl $\mathrm{Cp}_{2} \mathrm{Os}_{2} \mathrm{H}_{2}(\mathrm{CO})_{2}$ is the species that has been synthesized although the tricarbonyl $\mathrm{Cp}_{2} \mathrm{Os}_{2} \mathrm{H}_{2}(\mathrm{CO})_{3}$ could also be an feasible synthetic objective. None of the $\mathrm{Cp}_{2} \mathrm{Re}_{2} \mathrm{H}_{2}(\mathrm{CO})_{n}(n=3,2,1)$ derivatives are known 
experimentally. The rhenium derivative $\mathrm{Cp}_{2} \mathrm{Re}_{2} \mathrm{H}_{2}(\mathrm{CO})_{2}$ with a formal $\mathrm{Re} \equiv \mathrm{Re}$ triple bond has a very high predicted $\mathrm{CO}$ dissociation energy of $\sim 70 \mathrm{kcal} / \mathrm{mol}$ to give $\mathrm{Cp}_{2} \mathrm{Re}_{2} \mathrm{H}_{2}(\mathrm{CO})$ with a formal Re-Re quadruple bond. The $\mathrm{CO}$ dissociation energies suggest $\mathrm{Cp}_{2} \mathrm{Re}_{2} \mathrm{H}_{2}(\mathrm{CO})_{2}$ to be the most promising synthetic target. The experimental $\mathrm{CO}$ dissociation energies for the stable metal carbonyls $\mathrm{Ni}(\mathrm{CO})_{4}, \mathrm{Fe}(\mathrm{CO})_{5}$, and $\mathrm{Cr}(\mathrm{CO})_{6}$ of 27 , 41 , and $37 \mathrm{kcal} \cdot \mathrm{mol}^{-1}$, respectively, [40] can be compared with the predicted $\mathrm{CO}$ dissociation energies for the $\mathrm{Cp}_{2} \mathrm{M}_{2} \mathrm{H}_{2}(\mathrm{CO})_{n}(n=3,2)$ structures in Table 3 .

Table 3. $\mathrm{CO}$ dissociation energies $\left(\mathrm{kcal} \cdot \mathrm{mol}^{-1}\right)$ for $\mathrm{Cp}_{2} \mathrm{M}_{2} \mathrm{H}_{2}(\mathrm{CO})_{n}(\mathrm{M}=\mathrm{Ir}$, Os, Re; $n=1$, 2, 3) based on the lowest energy structures by the M06-L, MPW1PW91 and BP86 methods.

\begin{tabular}{ccc}
\hline \multicolumn{1}{c}{ Reaction } & Functional & $\begin{array}{c}\text { CO dissociation } \\
\text { energy }\end{array}$ \\
\hline & M06-L & 11.6 \\
$\mathrm{Cp}_{2} \mathrm{Ir}_{2} \mathrm{H}_{2}(\mathrm{CO})_{3} \rightarrow \mathrm{Cp}_{2} \mathrm{Ir}_{2} \mathrm{H}_{2}(\mathrm{CO})_{2}+\mathrm{CO}$ & BP86 & 11.9 \\
& MPW1PW91 & 8.7 \\
\hline $\mathrm{Cp}_{2} \mathrm{Ir}_{2} \mathrm{H}_{2}(\mathrm{CO})_{2} \rightarrow \mathrm{Cp}_{2} \mathrm{Ir}_{2} \mathrm{H}_{2}(\mathrm{CO})+\mathrm{CO}$ & M06-L & 46.0 \\
& BP86 & 48.5 \\
$\mathrm{Cp}_{2} \mathrm{Os}_{2} \mathrm{H}_{2}(\mathrm{CO})_{3} \rightarrow \mathrm{Cp}_{2} \mathrm{Os}_{2} \mathrm{H}_{2}(\mathrm{CO})_{2}+\mathrm{CO}$ & MPW1PW91 & 48.9 \\
\hline & M06-L & 32.4 \\
$\mathrm{Cp}_{2} \mathrm{Os}_{2} \mathrm{H}_{2}(\mathrm{CO})_{2} \rightarrow \mathrm{Cp}_{2} \mathrm{Os}_{2} \mathrm{H}_{2}(\mathrm{CO})+\mathrm{CO}$ & BP86 & 36.3 \\
& MPW1PW91 & 32.4 \\
\hline \multirow{2}{*}{$\mathrm{Cp}_{2} \mathrm{Re}_{2} \mathrm{H}_{2}(\mathrm{CO})_{3} \rightarrow \mathrm{Cp}_{2} \mathrm{Re}_{2} \mathrm{H}_{2}(\mathrm{CO})_{2}+\mathrm{CO}$} & M06-L & 37.2 \\
& BP86 & 40.9 \\
& MPW1PW91 & 41.5 \\
\hline $\mathrm{Cp}_{2} \mathrm{Re}_{2} \mathrm{H}_{2}(\mathrm{CO})_{2} \rightarrow \mathrm{Cp}_{2} \mathrm{Re}_{2} \mathrm{H}_{2}(\mathrm{CO})+\mathrm{CO}$ & M06-L & 30.9 \\
& BP86 & 28.2 \\
& MPW1PW91 & 32.8 \\
\hline
\end{tabular}

\subsection{NBO analysis}

The analogous lowest energy $\mathrm{Cp}_{2} \mathrm{M}_{2} \mathrm{H}_{2}(\mathrm{CO})_{n}(\mathrm{M}=\mathrm{Ir}$, Os, Re; $n=3,2,1)$ structures of are compared in Tables 4 to 6 with respect to the Wiberg bond indices (WBIs), determined by NBO analysis [41] as as well as the metal-metal distances, the formal metal-metal bond orders, and the presence of bridging carbonyl groups and/or hydrogen atoms. Previous studies [37] on the WBIs of metal carbonyls show that the WBIs are relatively low compared with the formal bond orders, particularly when the metal-metal bonds are bridged by carbonyl groups. 
Table 4. Wiberg bond indices (WBI) of the $\mathrm{Ir}-\mathrm{Ir}$ bonds, $\mathrm{Ir}-\mathrm{Ir}$ distances $(\AA)$, and the formal Ir-Ir bond orders in the $\mathrm{Cp}_{2} \mathrm{Ir}_{2} \mathrm{H}_{2}(\mathrm{CO})_{n}$ structures $(n=1,2,3)$ calculated at the M06-L level of theory.

\begin{tabular}{ccccc}
\hline & $\begin{array}{c}\text { Ir-Ir } \\
\text { WBI }\end{array}$ & $\begin{array}{c}\text { Ir-Ir } \\
\text { Distance }(\AA)\end{array}$ & $\begin{array}{c}\text { Bond } \\
\text { order }\end{array}$ & $\begin{array}{c}\text { Bridging } \\
\text { groups }\end{array}$ \\
\hline Ir-1CO-1S & 0.49 & 2.613 & 2 & $2 \mathrm{H}, 1 \mathrm{CO}$ \\
Ir-1CO-2S & 0.64 & 2.620 & 2 & $1 \mathrm{H}$ \\
Ir-1CO-3S & 0.64 & 2.623 & 2 & $1 \mathrm{H}$ \\
Ir-1CO-4S & 0.59 & 2.621 & 2 & $1 \mathrm{CO}, 1 \mathrm{H}$ \\
Ir-1CO-5S & 1.02 & 2.501 & 2 & None \\
Ir-1CO-6S & 1.02 & 2.507 & 2 & None \\
Ir-2CO-1S & 0.48 & 2.770 & 1 & None \\
Ir-2CO-2S & 0.49 & 2.779 & 1 & None \\
Ir-2CO-3S & 0.49 & 2.770 & 1 & None \\
Ir-2CO-4S & 0.32 & 2.855 & 1 & $2 \mathrm{H}$ \\
Ir-2CO-5S & 0.34 & 2.708 & 1 & $1 \mathrm{CO}$ \\
Ir-2CO-6S & 0.41 & 2.746 & 1 & $1 \mathrm{H}, 1 \mathrm{CO}$ \\
Ir-2CO-7S & 0.33 & 2.807 & 1 & $2 \mathrm{H}$ \\
Ir-2CO-8S & 0.32 & 2.850 & 1 & $2 \mathrm{CO}$ \\
Ir-2CO-9S & 0.33 & 2.721 & 1 & None \\
Ir-3CO-1S & 0.46 & 2.790 & 1 & $1 \mathrm{CO}$ \\
Ir-3CO-2S & 0.09 & 3.633 & 0 & $1 C O$ \\
Ir-3CO-3S & 0.08 & 3.706 & 0 & $1 \mathrm{CO}$ \\
Ir-3CO-4S & 0.09 & 3.662 & 0 & $1 \mathrm{CO}$ \\
Ir-3CO-5S & 0.08 & 3.756 & 0 & $1 \mathrm{CO}$ \\
Ir-3CO-6S & 0.09 & 3.641 & 0 & $1 \mathrm{CO}$ \\
Ir-3CO-7S & 0.29 & 2.829 & 1 & \\
\hline & & & & \\
\hline
\end{tabular}

For the unbridged iridium and osmium structures without the complication of bridging groups, the WBIs for formal double, and single metal-metal bonds in the $\mathrm{Cp}_{2} \mathrm{M}_{2} \mathrm{H}_{2}(\mathrm{CO})_{n}(\mathrm{M}=\mathrm{Ir}, n=2,1 ; \mathrm{M}=\mathrm{Os}, n=3)$ structures are $\sim 1.0$ and $\sim 0.5$, respectively (Tables 4 and 5). The WBIs for rhenium-rhenium bonds in the unbridged $\mathrm{Cp}_{2} \mathrm{Re}_{2} \mathrm{H}_{2}(\mathrm{CO})_{n}$ structures are somewhat lower for a given bond order, i. e. $\sim 0.6$ for the $\mathrm{Re}=\mathrm{Re}$ double bonds in the unbridged $\mathrm{Cp}_{2} \mathrm{Re}_{2} \mathrm{H}_{2}(\mathrm{CO})_{3}$ structures and $\sim 1.2$ to $\sim 1.8$ for the Re-Re quadruple bonds in the unbridged $\mathrm{Cp}_{2} \mathrm{Re}_{2} \mathrm{H}_{2}(\mathrm{CO})$ structures. Addition of bridging groups $(\mathrm{H}$ and/or $\mathrm{CO})$ across the metal-metal bonds lowers the WBIs significantly for a given bond order. Thus the WBIs for bridged triple, double, and single metal-metal bonds in the $\mathrm{Cp}_{2} \mathrm{M}_{2} \mathrm{H}_{2}(\mathrm{CO})_{\mathrm{n}}(\mathrm{M}=\mathrm{Ir}$, Os) structures are $\sim 0.7, \sim 0.5$, and $\sim 0.4$, respectively. The effect of bridging groups in lowering the effective metal-metal bond order as indicated by a lower WBI value has been attributed to multicenter bonding 
involving both metal atoms and the bridging atom(s) [42]. This phenomenon has been examined in greater depth by Ponec using domain averaged Fermi holes [43].

Table 5. Wiberg bond indices (WBI) of the Os-Os bonds, Os-Os distances $(\AA)$, and the formal Os-Os bond orders in the $\mathrm{Cp}_{2} \mathrm{Os}_{2} \mathrm{H}_{2}(\mathrm{CO})_{n}$ structures $(n=1,2,3)$ calculated at the M06-L level of theory.

\begin{tabular}{lcccc}
\hline & $\begin{array}{c}\text { Os-Os } \\
\text { WBI }\end{array}$ & $\begin{array}{c}\text { Os-Os } \\
\text { Distance }(\AA)\end{array}$ & $\begin{array}{c}\text { Bond } \\
\text { order }\end{array}$ & $\begin{array}{c}\text { Bridging } \\
\text { groups }\end{array}$ \\
\hline Os-1CO-1S & 0.77 & 2.490 & 3 & $2 \mathrm{H}, 1 \mathrm{CO}$ \\
Os-1CO-2S & 0.66 & 2.558 & 3 & $1 \mathrm{CO}$ \\
Os-2CO-1S & 0.51 & 2.710 & 2 & $2 \mathrm{H}$ \\
Os-2CO-2S & 0.50 & 2.727 & 2 & $2 \mathrm{H}$ \\
Os-2CO-3S & 0.63 & 2.695 & 2 & $1 \mathrm{H}$ \\
Os-3CO-1S & 0.47 & 2.891 & 1 & None \\
Os-3CO-2S & 0.49 & 2.887 & 1 & None \\
Os-3CO-3S & 0.41 & 2.842 & 1 & $1 \mathrm{CO}$ \\
Os-3CO-4S & 0.40 & 2.850 & 1 & $1 \mathrm{CO}$ \\
Os-3CO-5S & 0.48 & 2.895 & 1 & $1 \mathrm{CO}, 1 \mathrm{H}$ \\
Os-3CO-6S & 0.47 & 2.902 & 1 & None \\
Os-3CO-7S & 0.39 & 2.874 & 1 & $1 \mathrm{CO}$ \\
Os-3CO-8S & 0.40 & 2.856 & 1 & $1 \mathrm{CO}$ \\
Os-3CO-9S & 0.40 & 2.882 & 1 & $1 \mathrm{CO}$ \\
Os-3CO-10S & 0.33 & 2.810 & 1 & $2 \mathrm{CO}$ \\
\hline
\end{tabular}

Table 6. Wiberg bond indices (WBI) of the Re-Re bonds, Re-Re distances $(\AA)$, and the formal Re-Re bond orders in the $\mathrm{Cp}_{2} \mathrm{Re}_{2} \mathrm{H}_{2}(\mathrm{CO})_{n}$ structures $(n=1,2,3)$ calculated at the M06-L level of theory.

\begin{tabular}{lcccc}
\hline & \multicolumn{3}{c}{ M06-L(Re-Re) } \\
\hline & $\begin{array}{c}\text { Re-Re } \\
\text { WBI }\end{array}$ & $\begin{array}{c}\text { Re-Re } \\
\text { Distance }(\AA)\end{array}$ & $\begin{array}{c}\text { Bond } \\
\text { order }\end{array}$ & Bridging groups \\
\hline Re-1CO-1S & 1.54 & 2.451 & 4 & $2 \mathrm{H}, 1 \mathrm{CO}$ \\
Re-1CO-2S & 1.48 & 2.457 & 4 & $1 \mathrm{H}, 1 \mathrm{CO}$ \\
Re-1CO-3S & 1.24 & 2.478 & 4 & $1 \mathrm{H}, 1 \mathrm{CO}$ \\
Re-1CO-4S & 1.84 & 2.357 & 4 & $1 \mathrm{CO}(\mathrm{semi})$ \\
Re-2CO-1S & 0.97 & 2.483 & 3 & $2 \mathrm{CO}$ \\
Re-2CO-2S & 0.95 & 2.495 & 3 & $1 \mathrm{CO}, 1 \mathrm{H}$ \\
Re-2CO-3S & 1.07 & 2.461 & 3 & $2 \mathrm{CO}(\mathrm{semi})$ \\
Re-2CO-4S & 0.92 & 2.483 & 3 & $1 \mathrm{CO}, 1 \mathrm{H}, 1 \mathrm{CO}(\mathrm{semi})$ \\
Re-3CO-1S & 0.63 & 2.777 & 2 & $1 \mathrm{H}$ \\
Re-3CO-2S & 0.58 & 2.767 & 2 & $1 \mathrm{H}$ \\
Re-3CO-3S & 0.59 & 2.791 & 2 & $1 \mathrm{H}$ \\
Re-3CO-4S & 0.60 & 2.782 & 2 & $1 \mathrm{H}$ \\
Re-3CO-5S & 0.69 & 2.748 & 2 & $1 \mathrm{CO}(\mathrm{semi})$ \\
\hline
\end{tabular}




\section{Discussion}

The two experimentally known $\mathrm{Cp}_{2} \mathrm{M}_{2} \mathrm{H}_{2}(\mathrm{CO})_{n}(\mathrm{M}=\mathrm{Ir}$, Os, Re; $n=3,2,1)$ derivatives are both dicarbonyls $\mathrm{Cp}_{2}{ }_{2} \mathrm{M}_{2} \mathrm{H}_{2}(\mathrm{CO})_{2}(\mathrm{M}=\mathrm{Ir}$ [17], Os [16]) containing the permethylated $\mathrm{Cp}^{*}$ ligand. Our predicted low-energy structures for the corresponding unsubstituted $\mathrm{Cp}_{2} \mathrm{M}_{2} \mathrm{H}_{2}(\mathrm{CO})_{2}$ derivatives agree well with the experimental structures of the corresponding $\mathrm{Cp}^{*}{ }_{2} \mathrm{M}_{2} \mathrm{H}_{2}(\mathrm{CO})_{2}$ derivatives. Thus the low energy $\mathrm{Cp}_{2} \mathrm{Ir}_{2} \mathrm{H}_{2}(\mathrm{CO})_{2}$ structure Ir-2CO-2S (Figure 2), within $0.3 \mathrm{kcal} \cdot \mathrm{mol}^{-1}$ of the global minimum, has exclusively terminal $\mathrm{CO}$ and hydride ligands with an Ir-Ir distance of $\sim 2.8 \AA$ suggesting the formal single bond required to give the iridium atom the favored 18-electron configuration. However, the lowest energy $\mathrm{Cp}_{2} \mathrm{Os}_{2} \mathrm{H}_{2}(\mathrm{CO})_{2}$ structure Os-2CO-1S has the two hydrogen atoms bridging an Os=Os bond of length $\sim 2.71 \AA$ as compared with the experimental value of $\sim 2.68 \AA$ (Figure 5). Interpretation of this Os=Os interaction as a formal double bond gives each osmium atom the favored 18-electron configuration.

The central $\mathrm{Os}_{2}(\mu-\mathrm{H})_{2}$ unit in the $\mathrm{Cp}_{2} \mathrm{Os}_{2}(\mu-\mathrm{H})_{2}(\mathrm{CO})_{2}$ structure Os-2CO-1S may be regarded as a protonated double bond similar to the central $\mathrm{B}_{2}(\mu-\mathrm{H})_{2}$ unit in diborane, $\mathrm{B}_{2} \mathrm{H}_{6}=\mathrm{B}_{2}(\mu-\mathrm{H})_{2} \mathrm{H}_{4}$. The experimentally known [44] $\mathrm{Re}_{2}(\mu-\mathrm{H})_{2}(\mathrm{CO})_{8}$ has a similar doubly bridged $\operatorname{Re}_{2}(\mu-\mathrm{H})_{2}$ unit with an $\operatorname{Re}=\operatorname{Re}$ distance of $\sim 2.88 \AA$. The longer doubly bridged $\mathrm{Re}=\mathrm{Re}$ distance in $\operatorname{Re}_{2}(\mu-\mathrm{H})_{2}(\mathrm{CO})_{8}$ relative to the doubly bridged Os=Os distance in $\mathrm{Cp}_{2} \mathrm{Os}_{2}(\mu-\mathrm{H})_{2}(\mathrm{CO})_{2}$ can be related to the strong back-bonding of the "extra" $\mathrm{CO}$ groups in $\operatorname{Re}_{2}(\mu-\mathrm{H})_{2}(\mathrm{CO})_{8}$ relative to the $\mathrm{Cp}$ ligands in $\mathrm{Cp}_{2} \mathrm{Os}_{2}(\mu-\mathrm{H})_{2}(\mathrm{CO})_{2}$. This additional back-bonding can remove more electron density from the central $\mathrm{M}_{2}(\mu-\mathrm{H})_{2}$ unit in $\operatorname{Re}_{2}(\mu-\mathrm{H})_{2}(\mathrm{CO})_{8}$ relative to $\mathrm{Cp}_{2} \mathrm{Os}_{2}(\mu-\mathrm{H})_{2}(\mathrm{CO})_{2}$ thereby weakening the metalmetal interaction. Note that the $\mathrm{BH}_{2}, \mathrm{CpOs}(\mathrm{CO})$, and $\mathrm{Re}(\mathrm{CO})_{4}$ moieties in $\mathrm{B}_{2}(\mu-\mathrm{H})_{2} \mathrm{H}_{4}$, $\mathrm{Cp}_{2} \mathrm{Os}_{2}(\mu-\mathrm{H})_{2}(\mathrm{CO})_{2}$, and $\mathrm{Re}_{2}(\mu-\mathrm{H})_{2}(\mathrm{CO})_{8}$ are isoelectronic and isolobal.

The potential energy surfaces of some of the $\mathrm{Cp}_{2} \mathrm{M}_{2} \mathrm{H}_{2}(\mathrm{CO})_{n}(\mathrm{M}=\mathrm{Ir}$, Os, Re; $n=$ $3,2,1)$ derivatives are rather complicated with isomeric structures having different combinations of bridging $\mathrm{CO}$ and $\mathrm{H}$ ligands and trans and cis orientations of the $\mathrm{Cp}$ rings having energies within a few $\mathrm{kcal} \cdot \mathrm{mol}^{-1}$. However, the lowest energy structures of the monocarbonyls $\mathrm{Cp}_{2} \mathrm{M}_{2} \mathrm{H}_{2}(\mathrm{CO})(\mathrm{M}=\mathrm{Ir}$, Os, Re) are consistently triply bridged structures with all three ligands bridging the metal-metal bond. The $\mathrm{Cp}_{2} \mathrm{Os}_{2}(\mu-\mathrm{H})_{2}(\mu-\mathrm{CO})$ structure Os-1CO-1S of this type is particularly favorable, since it lies $\sim 36 \mathrm{kcal} \cdot \mathrm{mol}^{-1}$ in energy below the next lowest energy structure Os-1CO-2S (Figure 6). In the $\mathrm{Cp}_{2} \mathrm{M}_{2} \mathrm{H}_{2}(\mathrm{CO})_{n}$ (M $=\mathrm{Ir}$, Os, Re; $n=3,2,1)$ structures each hydrogen atom and each $\mathrm{CO}$ group are consistently donors of one and two electrons, respectively, regardless of whether they occupy terminal or bridging positions. This means that the complete series of isomeric $\mathrm{Cp}_{2} \mathrm{M}_{2} \mathrm{H}_{2}(\mathrm{CO})_{n}$ structures have the same formal M-M bond order. 
The 18-electron rule provides reasonable assignments for the formal metal-metal bond orders in the $\mathrm{Cp}_{2} \mathrm{M}_{2} \mathrm{H}_{2}(\mathrm{CO})_{n}(\mathrm{M}=\mathrm{Ir}$, Os, Re; $n=3,2,1)$ derivatives. Thus the $\mathrm{Cp}_{2} \mathrm{Ir}_{2} \mathrm{H}_{2}(\mathrm{CO})_{2}$ and $\mathrm{Cp}_{2} \mathrm{Os}_{2} \mathrm{H}_{2}(\mathrm{CO})_{3}$ systems have formal single metal-metal bonds. These typically have lengths ranging from $\sim 2.8$ to $2.9 \AA$. However, these become shorter approaching $\sim 2.7 \AA$ in the structures having bridging $\mathrm{CO}$ groups such as the higher energy $\mathrm{Cp}_{2} \mathrm{Ir}_{2} \mathrm{H}_{2}(\mathrm{CO})_{2}$ structures Ir-2CO-5S , Ir-2CO-6S, and Ir-2CO-9S. Similarly, the $\mathrm{Cp}_{2} \mathrm{Ir}_{2} \mathrm{H}_{2}(\mathrm{CO}), \mathrm{Cp}_{2} \mathrm{Os}_{2} \mathrm{H}_{2}(\mathrm{CO})_{2}$, and $\mathrm{Cp}_{2} \mathrm{Re}_{2} \mathrm{H}_{2}(\mathrm{CO})_{3}$ systems have formal double metalmetal bonds. These can range in length from $\sim 2.5$ to $2.6 \AA$ for $\mathrm{Cp}_{2} \mathrm{Ir}_{2} \mathrm{H}_{2}(\mathrm{CO}), \sim 2.7 \AA$ for $\mathrm{Cp}_{2} \mathrm{Os}_{2} \mathrm{H}_{2}(\mathrm{CO})_{2}$, and $\sim 2.8 \AA$ for $\mathrm{Cp}_{2} \mathrm{Re}_{2} \mathrm{H}_{2}(\mathrm{CO})_{3}$. There is here a definite increase in the $\mathrm{M}=\mathrm{M}$ double bond length as the number of $\mathrm{CO}$ groups is increased. This may be a consequence of the strong back-bonding $\mathrm{CO}$ ligands withdrawing electron density from the $\mathrm{M}=\mathrm{M}$ double bond.

The trend continues for the $\mathrm{Cp}_{2} \mathrm{M}_{2} \mathrm{H}_{2}(\mathrm{CO})_{n}$ systems with higher formal metalmetal bond orders. None of these systems have yet been realized experimentally. The 18-electron rule predicts formal $\mathrm{M} \equiv \mathrm{M}$ triple bonds for the $\mathrm{Cp}_{2} \mathrm{Os}_{2} \mathrm{H}_{2}(\mathrm{CO})$ and $\mathrm{Cp}_{2} \mathrm{Re}_{2} \mathrm{H}_{2}(\mathrm{CO})_{2}$ structures. Such triple bonds have lengths of $\sim 2.5 \AA$ and are bridged by two ligands in the lowest energy structures. At least one of these bridging ligands is a $\mathrm{CO}$ group.

The 18-electron rule predicts a formal Re-Re quadruple bond in the $\mathrm{Cp}_{2} \mathrm{Re}_{2} \mathrm{H}_{2}(\mathrm{CO})$ structures consistent with the relatively short Re-Re distances of $\sim 2.4 \AA$ and relatively high WBIs ranging from $\sim 1.2$ to $\sim 1.8$. The lowest energy $\mathrm{Cp}_{2} \mathrm{Re}_{2} \mathrm{H}_{2}(\mathrm{CO})$ structure Re-1CO-1S has all three ligands bridging the Re-Re bond as discussed above. However, the next three higher energy $\mathrm{Cp}_{2} \mathrm{Re}_{2} \mathrm{H}_{2}(\mathrm{CO})$ structures, lying $\sim 7 \mathrm{kcal} \cdot \mathrm{mol}^{-1}$ or more in energy above Re-1CO-1S, have at least one terminal hydrogen atom.

The 18-electron rule suggests absence of an iridium-iridium bond in the $\mathrm{Cp}_{2} \mathrm{Ir}_{2} \mathrm{H}_{2}(\mathrm{CO})_{3}$ structures. Five of the seven lowest-energy $\mathrm{Cp}_{2} \mathrm{Ir}_{2} \mathrm{H}_{2}(\mathrm{CO})_{3}$ structures from Ir-3CO-2S to Ir-3CO-6S, inclusive, have long non-bonding Ir ${ }^{\cdots} \mathrm{Ir}$ distances ranging from $\sim 3.63$ to $\sim 3.76 \AA$. However, the lowest-energy $\mathrm{Cp}_{2} \mathrm{Ir}_{2} \mathrm{H}_{2}(\mathrm{CO})_{3}$ structure Ir-3CO-1S as well as the higher energy structures Ir-3CO-7S have Ir-Ir bonding distances of $\sim 2.8 \AA$ consistent with a formal single bond. In Ir-3CO-1S the 18-electron configuration is maintained for each iridium atom by migration of a hydrogen atom from rhenium to carbon to give a one-electron donor formyl - $\mathrm{C}(\mathrm{O}) \mathrm{H}$ ligand. In Ir-3CO-7S the 18-electron configuration is maintained for each iridium atom by slippage of one of the $\mathrm{Cp}$ rings to become a trihapto $\eta^{3}-\mathrm{Cp}$ ligand rather than the usual pentahapto $\eta^{5}-\mathrm{Cp}$ ligand. However, the tricarbonyl $\mathrm{Cp}_{2} \mathrm{Ir}_{2} \mathrm{H}_{2}(\mathrm{CO})_{3}$ does not appear to be a very favorable system since its $\mathrm{CO}$ dissociation energy to give the known $\mathrm{Cp}_{2} \mathrm{Ir}_{2} \mathrm{H}_{2}(\mathrm{CO})_{2}$ is only $\sim 11 \mathrm{kcal} / \mathrm{mol}$. 


\section{Conclusions}

The $\mathrm{Cp}_{2} \mathrm{M}_{2} \mathrm{H}_{2}(\mathrm{CO})_{n}(\mathrm{M}=\mathrm{Ir}$, Os, Re; $n=3,2,1)$ systems, including the experimentally known and structurally characterized permethylated derivatives $\mathrm{Cp}_{2}{ }_{2} \mathrm{M}_{2} \mathrm{H}_{2}(\mathrm{CO})_{2}\left(\mathrm{Cp}^{*}=\eta^{5}-\mathrm{Me}_{5} \mathrm{C}_{5} ; \mathrm{M}=\mathrm{Ir}\right.$ [17], Os [16]), provide examples of binuclear structures having metal-metal bonds of formal orders ranging from zero to four consistent with the 18-electron rule. The low-energy $\mathrm{Cp}_{2} \mathrm{Ir}_{2} \mathrm{H}_{2}(\mathrm{CO})_{3}$ structures lacking a direct iridium-iridium bond necessarily have a bridging $\mathrm{CO}$ group holding together the two iridium atoms. For $\mathrm{Cp}_{2} \mathrm{Ir}_{2} \mathrm{H}_{2}(\mathrm{CO})_{2}$, low-energy unbridged structures are found corresponding to the experimental unbridged $\mathrm{Cp}^{*}{ }_{2} \mathrm{Ir}_{2} \mathrm{H}_{2}(\mathrm{CO})_{2}$ structure. However, for $\mathrm{Cp}_{2} \mathrm{Os}_{2} \mathrm{H}_{2}(\mathrm{CO})_{2}$ the lowest energy structure has two hydrogen atoms bridging the formal Os $=$ Os double bond similar to the experimental doubly bridged $\mathrm{Cp}^{*}{ }_{2} \mathrm{Os}_{2} \mathrm{H}_{2}(\mathrm{CO})_{2}$ structure. The central $\mathrm{Os}_{2}(\mu-\mathrm{H})_{2}$ protonated double bond is similar to the central $\mathrm{B}_{2}(\mu-\mathrm{H})_{2}$ protonated double bond in diborane. The lowest energy structures of the monocarbonyls $\mathrm{Cp}_{2} \mathrm{M}_{2} \mathrm{H}_{2}(\mathrm{CO})$ have all three ligands $(2 \mathrm{H}+\mathrm{CO})$ bridging a central metal-metal bond. The $\mathrm{Cp}_{2} \mathrm{Re}_{2} \mathrm{H}_{2}(\mathrm{CO})$ structures provide examples of both bridged and unbridged structures containing formal Re-Re quadruple bonds with highly bridged structures being preferred energetically.

Acknowledgments. We are indebted to the Excellent Young Scholars Research Fund of Beijing Institute of Technology (2012YG0202 and 2014CX04024), Beijing Natural Science Foundation (2132033, and 2132035), Beijing Higher Education Young Elite Teacher Project (YETP1177), the National Natural Science Foundation of China (U1530262) and the U.S. National Science Foundation (Grant CHE-1057466) for support of this research.

Supporting Information. Tables S1 to S9: Total energies (E, in hartree), relative energies $(\Delta \mathrm{E}$, in $\mathrm{kcal} / \mathrm{mol})$, numbers of imaginary vibrational frequencies (Nimag), and Ir-Ir distances $(\AA)$ for the optimized $\mathrm{Cp}_{2} \mathrm{M}_{2} \mathrm{H}_{2}(\mathrm{CO})_{n}(\mathrm{M}=\mathrm{Ir}$, Os, Re; $n=1,2,3)$ structures; Tables S10 to S12: Wiberg bond indices (WBIs) of bonds, bond distances, and the bond order analysis in the structures of $\mathrm{Cp}_{2} \mathrm{M}_{2} \mathrm{H}_{2}(\mathrm{CO})_{n}(\mathrm{M}=\mathrm{Ir}$, Os, Re; $n=1,2,3)$ calculated at the MPW1PW91 level of theory; Tables S13 to S64: Coordinates of the optimized $\mathrm{Cp}_{2} \mathrm{M}_{2} \mathrm{H}_{2}(\mathrm{CO})_{n}(\mathrm{M}=\mathrm{Ir}$, Os, Re; $n=1,2,3)$ structures; Tables S65 to S73: Harmonic vibrational frequencies of the optimized $\mathrm{Cp}_{2} \mathrm{M}_{2} \mathrm{H}_{2}(\mathrm{CO})_{n}(\mathrm{M}=\mathrm{Ir}$, Os, Re; $n=1$, 2, 3) structures; Complete Gaussian Reference. 


\section{Literature References}

[1] G. E. F. Lundell, H. B. Knowles, J. Res. Natl. Bur. Std. 18 (1937) 629.

[2] S. C. Abrahams, A. P. Ginsberg, K. Knox, Inorg. Chem. 3 (1964) 558.

[3] W. A. Herrmann, J. Okuda, Angew. Chem. Int. Ed. 25 (1986) 1092.

[4] W.A. Herrmann, H.G. Theiler, P. Kiprof, J. Tremmel, R. Blom, J. Organometal. Chem. 395 (1990) 69.

[5] C. L. Gross, G. S. Girolami, Organometallics 26 (2007) 160.

[6] T. M. Gilbert, R. G. Bergman, Organometallics 2 (1983) 1458.

[7] I. Langmuir, Science 54 (1921) 59.

[8] D. M. Bose, Z. Phys. 35 (1926) 219.

[9] F. Reiff, Z. Anorg. Allgem. Chem. 202 (1931) 375.

[10] N. V. Sidgwick, R. W. Bailey, Proc. Roy. Soc. London A144 (1934) 521.

[11] P. Pyykkö, J. Organometal. Chem. 691 (2006) 4336.

[12] Z. Hou, A. Fujita, T. Koizumi, H. Yamazaki, Y. Wakatsuki, Organometallics 18 (1999) 1979.

[13] T. S. Piper, G. Wilkinson, J. Inorg. Nucl. Chem. 3 (1956) 104.

[14] C. P. Casey, R. S. Tanke, P. N. Hazin, C. R. Kemnitz, R. J. McMahon, Inorg. Chem. 31 (1992) 5474.

[15] W. A. Herrmann, E. Herdtweck, A. Schaefer, Chem. Ber. 121 (1988) 1907.

[16] J. K. Hoyano, W. A. G. Graham, J. Am. Chem. Soc. 104 (1982) 3722.

[17] D. M. Heinekey, D. A. Fine, D. Barnhart, Organometallics 16 (1997) 2530.

[18] M. Brynda, L. Gagliardi, P. O. Widmark, P. P. Power, B. O. Roos, Angew. Chem. Int. Ed. 45 (2006) 3804.

[19] N. Sieffert, M. Bühl, J. Am. Chem. Soc. 132 (2010) 8056.

[20] P. Schyman, W. Lai, H. Chen, Y. Wang, S. Shaik, J. Am. Chem. Soc. 133 (2011) 7977.

[21] R. D. Adams, W. C. Pearl, Y. O. Wong, Q. Zhang, M. B. Hall, J. R. Walensky, J. Am. Chem. Soc. 133 (2011) 12994.

[22] R. Lonsdale, J. Olah, A. J. Mulholland, J. N. Harvey, J. Am. Chem. Soc. 133 (2011) 15464.

[23] L. Crawford, D. J. Cole-Hamilton, E. Drent, M. Bühl, Chem. Eur. J. 20 (2014) 13923.

[24] H. Zhekova, M. Krykunov, J. Autschbach, T. Ziegler, J. Chem. Theory Comput. 10 (2014) 3299.

[25] A. D. Becke, Phys. Rev. A 38 (1988) 3098.

[26] J. P. Perdew, Phys. Rev. B 33 (1986) 8822.

[27] C. Adamo, V. Barone, J. Chem. Phys. 108 (1998) 664.

[28] Y. Zhao, D. G. Truhlar, Theor. Chem. Acc. 120 (2008) 215.

[29] Y. Zhao, N. E. Schultz, D. G. Truhlar, J. Chem. Phys. 123 (2005) 188. 
[30] T. V. Voorhis, G. E. Scuseria, J. Chem. Phys. 109 (1998) 400.

[31] S. Zhao, W. Wang, Z. Li, Z. P. Liu, K. Fan, Y. Xie, H. F. Schaefer, J. Chem. Phys. 124 (2006) 184102.

[32] V. Jonas, W. Thiel, J. Chem. Phys. 102 (1995) 8474.

[33] I. Silaghi-Dumitrescu, T. E. Bitterwolf, R. B. King, J. Am. Chem. Soc. 128 (2006) 5342.

[34] B. S. Narendrapurapu, N. A. Richardson, A. V. Copan, M. L. Estep, Z. Yang, H. F. Schaefer, J. Chem. Theory Comput. 9 (2013) 2930.

[35] T. H. Dunning, J. Chem. Phys. 53 (1970) 2823.

[36] S. Huzinaga, J. Chem. Phys. 42 (1965) 1293.

[37] M. Dolg, H. Stoll, H. Preuss, Theor. Chim. Acta. 85 (1993) 441.

[38] A. Bergner, M. Dolg, W. Kuechle, H. Stoll, H. Preuss, Mol. Phys. 80 (1993) 1431.

[39] M. J. Frisch, et al. Gaussian 09, Gaussian, Inc., Wallingford CT, 2009

[40] L. S. Sunderlin, D. Wang, R. R. Squires, J. Am. Chem. Soc. 115 (1993) 12060.

[41] F. Weinhold, C. R. Landis, Cambridge University Press, Cambridge, England, U. K., (2005), pp. 32.

[42] J.C. Green, M. L. H. Green, G. Parkin, Chem. Commun. 48 (2012) 11481.

[43] R. Ponec, G. Lendvay, J. Chaves, J. Comput. Chem. 29 (2008) 1387.

[44] N. Masciocchi, A. Sironi, J. Am. Chem. Soc. 112 (1990) 9395. 


$$
x
$$

